\title{
Inhibition of Inositol Polyphosphate Kinases by Quercetin and Related Flavonoids: A Structure/Activity Analysis.
}

\author{
Chunfang Gu${ }^{1}$, Michael A. Stashko², Ana C. Puhl-Rubio ${ }^{2}$, Molee Chakraborty ${ }^{3}$, Anutosh \\ Chakraborty $^{3}$, Stephen V. Frye ${ }^{2}$, Kenneth H. Pearce ${ }^{2}$, Xiaodong Wang ${ }^{2}$, Stephen B. Shears ${ }^{*}$, \\ 1 , and Huanchen Wang ${ }^{*}, 1$ \\ ${ }^{1}$ Inositol Signaling Group, Signal Transduction Laboratory, National Institute of Environmental, \\ Health Sciences, Research Triangle Park, NC, 27709 USA. \\ ${ }^{2}$ Center for Integrative Chemical Biology and Drug Discovery, Division of Chemical Biology and \\ Medicinal Chemistry, Eshelman School of Pharmacy, University of North Carolina at Chapel Hill, \\ Chapel Hill, NC 27599, USA. \\ 3Department of Pharmacology and Physiology, Saint Louis University School of Medicine, M370, \\ Schwitalla Hall; 1402 South Grand Blvd, Saint Louis, Missouri, 63104, USA.
}

\section{Abstract}

Dietary flavonoids inhibit certain protein- and phospholipid-kinases, by competing for their ATPbinding sites. These nucleotide pockets have structural elements that are well-conserved in two human small-molecule kinases, inositol hexakisphosphate kinase (IP6K) and inositol polyphosphate multikinase (IPMK), which synthesize multifunctional inositol-phosphate cellsignals. Herein, we demonstrate that both kinases are inhibited by quercetin and 16 related flavonoids; IP6K is the preferred target. Relative inhibitory activities were rationalized by X-ray analysis of kinase/flavonoid crystal-structures; this detailed structure/activity analysis revealed hydrophobic and polar ligand/protein interactions, the degree of flexibility of key amino-acid sidechains, and the importance of water molecules. The seven most potent IP6K inhibitors were incubated with intact HCT116 cells at concentrations of $2.5 \mu \mathrm{M}$; diosmetin was the most selective and effective IP6K inhibitor ( $>70 \%$ reduction in activity). Our data can instruct on pharmacophore properties to assist the future development of inositol-phosphate kinase inhibitors. Finally, we propose that dietary flavonoids may inhibit IP6K activity in cells that line the gastrointestinal tract.

\section{Graphical Abstract}

\footnotetext{
*Authors for correspondence: Stephen B. Shears; shears@ niehs.nih.gov; 984-2873-3483, Huanchen Wang: Huanchen.wang@nih.gov. ANCILLARY INFORMATION PDB ID codes

The accession codes for hIPMK/ligand crystal complexes have been deposited with the PDB as follows (ligands in parentheses): 6M88 (1; myricetin), 6M89 (2; quercetin), 6M8A (3; luteolin), 6M8B (4; kaemferol), 6M8C (6; isorhamnetin), 6M8D (7; diosmetin), $6 \mathrm{M} 8 \mathrm{E}$ (11; rhamnetin). The authors will release the atomic coordinates and experimental data upon article publication.
} 


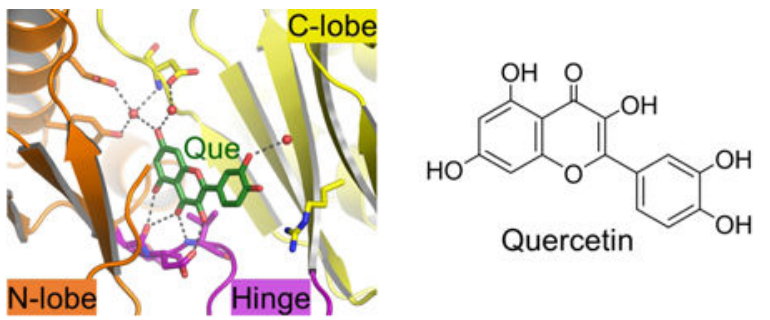

\section{Keywords}

kinase; flavonoid; pharmacology; inositol-phosphate

\section{INTRODUCTION}

All eukaryotes express a number of inositol phosphate (InsP) kinases (Fig. 1). These enzymes synthesize a range of diffusible messenger molecules which contain various combinations of phosphate groups, all attached to the inositol ring ${ }^{1-3}$. Valuable information concerning InsP function and metabolism has been derived from the creation of a number of InsP kinase knockouts, both in model organisms ${ }^{3-4}$ and in human cell lines ${ }^{3,5}$. However, all physiological actions of InsP kinases are not simply related to their catalytic activities; in addition, these proteins exhibit a variety of functionally-significant protein-protein interactions ${ }^{2-3}$. These are phenomena that complicate the use of genetic procedures to explore InsP biology; the phenotype that arises from a "knock-down" of kinase expression may not simply reflect a loss of InsP synthesis, but also the elimination of its scaffolding activities. Thus, there is growing need to develop cell-permeable inhibitors of the individual InsP kinases; such compounds could be very insightful in specifically deciphering the catalytic roles of these signaling enzymes ${ }^{6-9}$, and may also lead to the development of therapeutically-beneficial inhibitors ${ }^{3}$. For example, human inositol hexakisphosphate kinases (hIP6Ks; Fig. 1) synthesize the inositol pyrophosphate, $\operatorname{InsP}_{7}{ }^{10}$, a multifunctional molecule that receives particular attention, both for its ability to pyrophosphorylate proteins 11, and for its roles in bioenergetic homeostasis, cancer, and aging ${ }^{3,12}$. A close relative of the IP6Ks is inositol polyphosphate multikinase (IPMK; Fig. 1), a key enzyme in the pathway of $\mathrm{InsP}_{6}$ synthesis. IPMK is a transcriptional regulator, and its phosphorylation of $\mathrm{InsP}_{3}$ to InsP $\mathrm{P}_{5}$ produces a co-activator of the $\mathrm{Wnt} / \beta$-catenin signaling pathway ${ }^{13-14}$. Furthermore, there is growing interest in the substantial contributions that pathogenic fungal and protozoan InsP kinases make to the fitness and virulence of these organisms. It has become a viable proposition to develop drugs that can specifically target microbial InsP kinases, due to their limited homology with human orthologs $15-16$

Despite the enormous potential value of InsP kinase inhibitors, work to produce such molecules is in its infancy. One such compound, 2-[3,5-Dimethyl-1-(4- nitrophenyl)-1Hpyrazol-4-yl]-5,8-dinitro-1H-benzo[de]isoquin-oline-1,3(2H)-dione (BIP-4), inhibits IP3Ks (Fig. 1) ${ }^{9,17}$. However, the target specificity profile of BIP-4 is unknown, while its polar nitro groups impede cellular uptake and are potentially toxic in vivo ${ }^{9,17}$. Only one other InsP kinase inhibitor is in current use: $N 2$-( $m$-(trifluoromethyl)benzyl) $N 6$-( $p$ nitrobenzyl)purine (TNP), which is a competitive inhibitor of the ATP-binding site of 
inositol hexakisphosphate $\left(\mathrm{InsP}_{6}\right)$ kinases (IP6Ks) ${ }^{6}$. Unfortunately, TNP also has substantial limitations, including a growing list of off-target effects: inhibition of cytochrome $\mathrm{P} 450^{18}$, inhibition of CaMK $1{ }^{7}$, initiation of cellular Ca2+ fluxes ${ }^{19}$, and perturbation of the activity of the ERK protein kinase ${ }^{20-21}$. An additional restriction on the utility of TNP is that it inhibits all three IP6K isoforms ${ }^{3}$. The future development of isoform-specific IP6K inhibitors is an important future goal.

A new direction for the development of inhibitors of human IPMK (hIPMK) and InsP6Ks (hIP6K) has recently emerged from structural work which has demonstrated that these kinases exhibit substantial conservation of the protein-kinase fold, and in particular the ATPbinding site ${ }^{7,22-24}$. Thus, prior development of protein kinase inhibitors that block nucleotide binding has established a knowledge-base that could be applied productively to the design of new inhibitors that compete for the ATP-binding site of InsPKs ${ }^{7}$. To implement this approach through rational design, we need as much insight as possible into the pharmacophore space that is available. To this end, the flavonoids are one well-known group of competitive inhibitors of ATP-binding by protein kinases ${ }^{25-27}$. Flavonoids (Fig. 2) are low-molecular weight, aromatic compounds that are components of fruits, vegetables, and other plant components. It is possible that inhibition of protein kinases by flavonoids contributes to their reported ability to reduce the risks of cardiovascular disease, diabetes and cancer ${ }^{26-28}$. Flavonoids have other targets; they inhibit the structurally-similar phosphatidylinositol 3-kinase- $\gamma(\mathrm{PI} 3 \mathrm{~K} \gamma)^{25},{ }^{28-29}$, and they also interact with unrelated, nonkinase targets, such as mammalian $\mathrm{F}_{1}$-ATPase ${ }^{30}$, xanthine oxidase ${ }^{31}$, serine protease ${ }^{32}$ and telomeric DNA ${ }^{33}$. This promiscuity limits the value of the flavonoid core structure per se as the basis for a specific kinase inhibitor, but it is still recognized that valuable pharmacophore information can be obtained from a structure/activity analysis of the interactions of flavonoids with the ATP-binding pocket of a particular kinase ${ }^{27}$.

In the current study, our goal has been to assemble a logically-derived, analogue series of flavonoids that are based on $\mathbf{1}$ (Fig. 2), and to test their effects upon the catalytic activities of hIP6K2 and hIPMK. We have supported this work with orthogonal assays. We also sought to rationalize the inhibitory properties of our selection of flavonoids through the generation of $\mathrm{X}$-ray crystallographic data. Flavonoids also have the advantage of penetrating across the plasma membrane ${ }^{34}$, which has allowed us to investigate if their inhibition of InsP kinases can be recapitulated in intact cells. Our rigorous structure/activity analysis has allowed us to derive pharmacophore insights for future development of non-flavonoid inhibitors that can be made specific to a particular kinase target. Finally, our data also suggest previously unsuspected biological functionality for dietary flavonoids, as inhibitors of InsP kinases.

\section{A structure/activity analysis of the inhibition of hIP6K2 by flavonoids.}

The ATP-binding sites of hIP6Ks and hIPMK are similar to those of protein kinases ${ }^{22}$, which are inhibited by flavonoids ${ }^{26-27}$. Thus, a goal for this study was to perform a structure/activity analysis to investigate if the flavonoid core structure can provide new chemical information to apply to the development of novel inhibitors of InsP kinases. We began this work by investigating if $\mathbf{2}$ is an inhibitor of hIP6K2. As in our earlier study of hIP6K2 activity ${ }^{7}$, we used a time-resolved fluorescence resonance energy transfer (TR- 


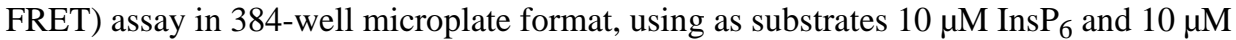
ATP. It should be noted that these assays all contained $0.01 \%$ Brij-35. The use of detergent prevents false-positive inhibition through colloidal aggregation of flavonoids into "pan assay interference compounds" (PAINS) ${ }^{35-37}$.

We discovered that 2 inhibits hIP6K2 activity with an $\mathrm{IC}_{50}$ value of $0.7 \mu \mathrm{M}$ (Table 1 ). We followed up this observation by examining the effects upon hIP6K2 of a range of flavonoids (Fig. 2), in order to determine the structural determinants for inhibition of kinase activity.

We found that addition of a 5'-OH group to 2 (yielding 1 ), had no impact upon the value of the $\mathrm{IC}_{50}$ (Table 1). This observation that $\mathbf{1}$ is an inhibitor of hIP6K2 confirms a prior report 8; nevertheless, in the latter study IP6K was also incubated with $\mathbf{2}$, and no inhibitory effect was observed, contrary to one of the findings in the current study (Table 1). Removal of the 3-OH group from 2 (yielding 3 ) results in a small (1.9-fold) decrease in inhibitory activity. A larger increase in the $\mathrm{IC}_{50}$ value (3.6-fold) is observed for removal of the 3'-OH (compare 4 with 2). The degree of the impact upon the $\mathrm{IC}_{50}$ value of removing from 2 both the 3-and the 3'-OH groups (yielding $\mathbf{5}$ ) is approximately additive, compared to loss of either group alone: a 10 -fold higher $\mathrm{IC}_{50}$ value for $\mathbf{5}$, compared to $\mathbf{2}$ (Table 1 ). We also found that the 7 $\mathrm{OH}$ group has an important role: for example, in a comparison of $\mathbf{9}$ with $\mathbf{3}$, loss of the 7-OH results in a 6-fold increase in the $\mathrm{IC}_{50}$ value (Table 1).

In some cases, $\mathrm{O}$-methylation was better tolerated than loss of the equivalent $\mathrm{OH}$ group. For example, 3'-O-methylation of $\mathbf{2}$ (as in $\mathbf{6}$ ) did not significantly alter the degree of inhibition of hIP6K2 (Table 1). O-methylation can also be tolerated by the OH group at the 4' position (similar $\mathrm{IC}_{50}$ data were obtained for $\mathbf{7}$ compared to $\mathbf{3}$, and for $\mathbf{8}$ compared to $\mathbf{5}$; Table 1). On the other hand, the conversion of the 7-OH to a 7-O-methyl group does slightly impact inhibition of hIP6K2: 10 exhibits a 3-fold higher $\mathrm{IC}_{50}$ than 5, and $\mathbf{1 1}$ shows a 2.6-fold higher $\mathrm{IC}_{50}$ than 2 (Table 1).

It is also significant that flavonoids with only two $\mathrm{OH}$ groups and no O-methyl groups (12, $\mathbf{1 3}, \mathbf{1 4}$, and 15) are all relatively weak inhibitors of hIP6K2 (Table 1). In fact, we are unable to ascertain with accuracy the exact $\mathrm{IC}_{50}$ value against hIP6K2 for $\mathbf{1 4}$ (and also 17; see below). This is an inherent technical issue, due in part to the relatively weak inhibition. Another likely contributory factor is the poor solubility of certain flavonoids at higher concentrations. For example, $\mathbf{1 4}$ and $\mathbf{1 7}$ are among the most hydrophobic of the flavonoids that we tested.

Finally, inhibitory activity against hIP6K2 is attenuated by reduction of the double bond between $\mathrm{C} 2$ and $\mathrm{C} 3$, and the concomitant disruption to the planarity of the chromen-4-one and phenyl rings. This is evident from a comparison of $\mathbf{1 6}$ with $\mathbf{3}$ (the latter has a 19-fold lower $\mathrm{IC}_{50}$ value against hIP6K2; Table 1). Consistent with the latter conclusion, $\mathbf{1 7}$ is at least 4-fold weaker an inhibitor than is $\mathbf{5}$ (Table 1).

\section{Comparative effects of flavonoids upon the inhibition of hIP6K2 and hIPMK.}

IPMK is the InsP kinase that is most closely related to the IP6Ks, both structurally ${ }^{22-24}$, and in an evolutionary context ${ }^{38}$. Thus, we selected IPMK to investigate to what extent the 
flavonoid scaffold might give insight into the principle of developing target specificity against an InsP kinase. In these experiments we used $10 \mu \mathrm{M}$ ATP and $10 \mu \mathrm{M} \mathrm{InsP}_{3}$ as substrates (Table 1).

Each of the flavonoids that we have examined were less potent against hIPMK than against hIP6K2, albeit to various degrees (Table 1). This is useful information, as it underscores that it is plausible to develop inhibitors that are more selective for IP6Ks. Furthermore, we identified some modifications to the flavonoid core structure that somewhat increase the relative degree of inhibition of hIP6K2 compared to that for hIPMK (see Table 1): Omethylation of the 4'-OH of $\mathbf{3}$, yielding $\mathbf{7}$, elicited a 1.9-fold improvement in selectivity for hIP6K2, and O-methylation of the 7-OH of $\mathbf{2}$, yielding $\mathbf{1 1}$, increased selectivity 2.4-fold (Table 1). Conversely, the addition of a 5'-OH group to 2 (i.e., conversion to 1 ), resulted in a 2-fold decrease in selectivity against hIP6K2 vs hIPMK (Table 1).

Finally, as is the case with hIP6K2, disruption to the planarity of the chromen-4-one and phenyl rings also impacts the degree of inhibition of hIPMK. For example, compare 16 with 3 (>5.5-fold loss of activity; Table 1).

\section{Structural rationalization of quercetin-mediated inhibition of hIPMK}

We next performed structural studies to rationalize the molecular recognition processes that underlie the inhibition of hIPMK by $\mathbf{2}$, which we successfully soaked into crystals of apohIPMK (Fig. 3A,B). The electron density of $\mathbf{2}$ assumes a crescent-like cross-section within the nucleotide-binding pocket, with the larger chromen-4-one group penetrating deeper, leaving the smaller phenyl group closest to the entrance (Fig. 3A,B,C). By comparing this new structure of the hIPMK/2 complex with that of hIPMK/ADP ${ }^{23}$, we observed that the chromen-4-one group is coplanar with the adenine group of ADP (Fig. 2C). This direct demonstration of competition by $\mathbf{2}$ for the nucleotide binding site provides a logical explanation for its inhibition of an InsP kinase, thereby countering concern that this activity of the flavonoid might involve experimental artifacts (i.e., PAINS ${ }^{35}$ ).

Moreover, the orientation of $\mathbf{2}$ within the nucleotide-binding pocket of hIPMK allows the flavonoid's ketone group to be positioned similarly to that of the N1 of ATP, so that the inhibitor can act as a surrogate by accepting a hydrogen bond from the hinge region of the protein (Fig. 3B-G). This situation is typical of the orientation of flavonoids within proteinkinases and PI3Ks ${ }^{25}$. We also ascertained that the ribose group of ADP is displaced at approximately $120^{\circ}$ from the phenyl group of $\mathbf{2}$. There is no overlap of $\mathbf{2}$ with the diphosphate group of ADP.

We identify several polar contacts of $\mathbf{2}$ with hIPMK that can account for the inhibitory activity of this particular ligand. The 7-OH of 2 lies at the interface of the $\mathrm{C}$ - and $\mathrm{N}$-lobes (Fig 3C), where it makes a hydrogen bond with two adjacent water molecules, which we have labeled as Wat1 and Wat2 (Fig. 3B). A third water molecule (Wat3; Fig. 3B) is associated with this hIPMK/2 complex through a single hydrogen bond with the 3 '-OH group. The identification of water molecules that contribute to ligand binding and target selectivity can be a significant step in inhibitor development ${ }^{39}$; such information is missing from the previously-published nucleotide-bound structure ${ }^{23}$. 
Wat1 is particularly well-coordinated, forming four hydrogen bonds, with E86 and Y90 from the N-lobe, D385 from the C-lobe, and the 7-OH of 2 (Fig. 3B). Wat2 is also involved in ligand binding, as it makes hydrogen bonds with D385 and the 7-OH of 2 (Fig. 3B). In the latter structure, D385 adopts the conformation that we previously observed in the inactive apoenzyme $(\mathrm{PDB}=5 \mathrm{~W} 2 \mathrm{G})^{23}$. This is an alternate rotamer, compared to its orientation in the nucleotide-bound state (Fig. 3G), in which D385 is a member of an ion-paired, catalytic triad of residues that activates $\mathrm{Mg}$ and interacts with the $\alpha$ and $\beta$ phosphates of ATP ${ }^{22-23}$.

Elsewhere in 2, the 3- and 5-OH groups, as well as the 4-keto group, all make hydrogenbonds with the polypeptide backbone at the $\mathrm{N}$-terminus of the hinge region. Interestingly (see below), we report that the 4'-OH group of 2 is $4.1-4.2 \AA$ distant from the R182 sidechain, just outside the $4 \AA$ distance that is typically considered the maximum possible range of a hydrogen bond ${ }^{40}$.

In addition to the polar contacts between hIPMK and 2 (Fig. 3B,D), the latter also has Van der Waals interactions (Fig. 3D) with residues in the N-lobe (I65, V73, K75, P111 and L130), the hinge region (T134), and the C-lobe (I142, L254, I384). We also draw attention to a number of amino acids in hIPMK that interact with 2, but not with ADP: I65, E86, Y90, T134, I142, and I384 (Fig. 3D). These data also provide more information on the pharmacophore space than is evident from our previously-published analysis of the nucleotide/hIPMK crystal complex ${ }^{23}$.

\section{A comparative analysis of the relative spatial orientation of 2 in crystal complexes with various kinases.}

The rational design of an inhibitor that might be specific for one particular kinase requires the identification of molecular recognition processes that are unique to that target. This approach cannot yet be deployed to assist development of inhibitors that can select between hIPMK and hIP6Ks, since no experimentally-determined structures for the latter are available. So instead we have docked $\mathbf{2}$ into a previously constructed homology model of hIP6K2 ${ }^{24}$ (Fig. 4A). This model predicts that 2 adopts comparable orientations in hIP6K2 and hIPMK (Fig. 3A,C; Fig. 4).

Data in the literature show the structures of $\mathbf{2}$ in complex with PI3K $\gamma^{25}$ and some proteinkinases $41-42$. Among these, the orientation of $\mathbf{2}$ in the HCK/2 complex 42 is closest to the pose of 2 in the hIPMK/2 complex (Fig. 3A, 4B). In both cases, the 5-OH, 7-OH and the keto group all make hydrogen bonds with the respective hinge regions. Despite these similarities, the relative position of $\mathbf{2}$ in $\mathrm{HCK}$ is rotated approx. $50^{\circ}$ relative to its position in hIPMK (Fig. 3B). There are other kinases that show more dramatic differences in the orientation of $\mathbf{2}$ in the ATP-binding pocket, as compared to that for hIPMK. For example, relative to the pose of $\mathbf{2}$ in hIPMK, there is a transposition of the relative positions of the phenyl ring and the chromen-4-one group, in crystal complexes of $\mathbf{2}$ with either PIM1, DAPK1 and PI3K $\gamma$, such that it is the phenyl ring that now makes polar contacts with the Nlobe (Fig. 4C,D,E). Moreover, compared to the orientation of $\mathbf{2}$ in hIPMK, the DAPK1/2 crystal complex shows that the chromen-4-one group has flipped $180^{\circ}$ such that its keto group is now distal to the hinge region (Fig. 4D). 
These various similarities and differences in inhibitor orientation, as well as the accompanying alternate polar and hydrophobic interactions, together offer new directions for the design of an inhibitor that may show specificity for an InsP kinase over protein-kinases and PI3Ks.

\section{Structural insights into inhibition of hIPMK by flavonoids.}

The rationalization of the inhibitory profiles of various flavonoids upon one particular InsP kinase (as in Table 1) can be confounded if the different ligands adopt alternate configurations within one protein's nucleotide-binding site, as is the case for both $\mathrm{PI} 3 \mathrm{~K} \gamma{ }^{25}$ and some protein- kinases ${ }^{41}$. Thus, in addition to compound 2 (Fig. 3B, and see above), we soaked into crystals of hIPMK the other six most potent inhibitors of this kinase (Fig. 5A-F; Table 1). Such an approach acts as an orthogonal validation of the inhibitory data. Additionally, a thorough structure/activity analysis "is the most important criterion" for excluding experimental artifacts (i.e., PAINS ${ }^{35}$ ).

One of three water molecules in the hIPMK/2 complex, Wat3, is associated through a single hydrogen bond to the 3'-OH (Fig. 3B). Removal of the latter OH group (in 4) is associated with loss of Wat3 (Fig. 5B) and a 2-fold reduction in inhibitory activity (Table 1). Wat3 is also missing from the hIPMK/6 structure (Fig. 2A;5C), but interestingly, there is a rotamer switch in the ligand's phenyl ring, such that the 3'-O-methyl group provides a gain of function $3.4 \AA$ hydrophobic interaction with I142 (Fig. 5C). We are not aware of any previous descriptions of this particular rotamer switch. This phenomenon may explain why 6 and $\mathbf{2}$ are equipotent inhibitors of hIPMK (Table 1), even though Wat 3 is missing from the hIPMK/6 complex. Moreover, the 3'-O-methyl group in 6, by increasing compound hydrophobicity, is also expected to increase bioavailability by improving passive uptake across the cell membrane.

In the other hIPMK/ligand structural complexes (Fig. 5), the orientations of the core structure of the various inhibitors show only subtle variations. These data give significant insight into several determinants of kinase inhibition. For example, we obtained structural complexes of hIPMK with $\mathbf{3}$ and $\mathbf{7}$ (Fig. 5E,F). The latter lack the 3-OH that, in 1, 2, 4, 6 and 11, forms a hydrogen bond interaction with the hinge region (Fig 3B, 5A,B,C,D). These results may at least partly explain why the $3-\mathrm{OH}$ makes about a 2 -fold contribution to the degree of inhibition (i.e., compare the hIPMK $\mathrm{IC}_{50}$ data for $\mathbf{2}$ and $\mathbf{3}$ in Table 1). Additional structural consequences appear to arise from the absence of the 3-OH in $\mathbf{3}$ and 7: there is a change in the atomic-level pivot point at which these flavonoids interacts with the hinge region, that may cause distal conformational changes that account for the loss of Wat2 (Fig. 3B; 5E,F). These are further observations that help define the pharmacophore space. In any case, $\mathbf{3}$ and $\mathbf{7}$ exhibit $\mathrm{IC}_{50}$ values against hIPMK that are 2.4- to 3-fold higher than that for $\mathbf{2}$ (Table 1).

We found that the addition of the 5'-OH to 2 (which yields 1), combines with the 4'-OH to form a pincer of hydrogen bonds that brings R182 closer to the phenyl ring (Fig. 5A). This can explain why $\mathbf{1}$ is an approximately 2 -fold stronger inhibitor of hIPMK than is $\mathbf{2}$ (Table 1). In addition, these data reveal further information about the pharmacophore space, by 
showing that the side-chain of R182 has flexibility in this structure. This contrasts with the side chains in the hinge region, which appear more rigid, since their orientations are unaffected by changes in the nature of the ligand (Fig. 5).

The hIPMK/11 crystal complex, in which the 7-OH group of $\mathbf{2}$ is methylated, provides another example of loss of Wat3 (Fig. 5D). However, the accompanying loss of Wat1 and Wat 2 would seem to have more structurally significant consequences, since this eliminates a significant hydrogen bond network (Fig. 3B; 5D); the latter effect probably makes the largest contribution to the 6-fold higher $\mathrm{IC}_{50}$ value for hIPMK inhibition by $\mathbf{1 1}$, compared to that for $\mathbf{2}$ (Table 1). Note also that D385 remains in its catalytically inactive configuration (see above) in all of the hIPMK/flavonoid crystal complexes (Fig. 5).

\section{The effects of flavonoids upon levels of inositol phosphates in intact cells.}

Each of the flavonoids that we have examined in this study are inherently less effective at inhibiting hIPMK than hIP6K2 (Table 1). In addition, IP6Ks have a much lower affinity for ATP than do IPMKs 10,43 , rendering the latter less susceptible to ATP-competing inhibitors at physiological (1-5mM) levels of this nucleotide. Thus (see Fig. 1), we hypothesized that the addition of flavonoids to intact cells would have a greater impact upon IP6K activity (i.e., synthesis of $\operatorname{InsP}_{7}{ }^{10}$ ) than IPMK activity (synthesis of $\operatorname{InsP}_{5}{ }^{44}$ ). To interrogate this idea in a physiologically-relevant context, we used HCT116 colonic epithelial cells, because they are a highly appropriate model of the human body's frontline exposure to significant levels of dietary flavonoids ${ }^{45}$. Indeed, there is considerable interest in the apparent protection from colon cancer afforded by these natural compounds ${ }^{46}$. Our treatment of HCT116 cells with the unconjugated flavonoids is also biologically relevant because conjugation hinders their passive diffusion into cells that line the gastrointestinal tract ${ }^{34,45}$. Furthermore, the HCT116 model is especially pertinent to the current study in that the type 2 isoform of hIP6K that we have studied in vitro (Table 1) is responsible for approx. $90 \%$ of all $\mathrm{InsP}_{7}$ synthesis in this cell-type ${ }^{47}$. Finally, InsP kinases are located in cell cytoplasm, and therefore not susceptible to possible non-specific effects of flavonoids resulting from their partition into membrane bilayers 48 .

We performed Carbopac-HPLC analysis of $\left[{ }^{3} \mathrm{H}\right]$-prelabeled HCT116 cells to record levels of $\mathrm{InsP}_{5}, \mathrm{InsP}_{6}$ and $\mathrm{InsP}_{7}$ (open circles in Fig. 6A); we initially treated cells with 2 . The concentrations of $\mathbf{2}$ in serum seem unlikely to surpass $1 \mu \mathrm{M}$ levels, even after dietary supplementation ${ }^{49}$, although cells that line the small intestine and colon are exposed to higher levels ${ }^{45,50}$. We incubated cells with $1-10 \mu \mathrm{M} 2$ for $3.5 \mathrm{hr}$, which caused dosedependent reductions in $\mathrm{InsP}_{7}$ levels (Fig 6A), indicative of inhibition of cellular hIP6K2 activity. A dose of $10 \mu \mathrm{M}$ of 2 reduced $\mathrm{InsP}_{7}$ levels by $90 \%$ (Fig. $6 \mathrm{~A}$ ); Ins $\mathrm{P}_{6}$ levels were not affected, while InsP $\mathrm{P}_{5}$ levels were reduced by approx. 25\% (Fig. 6A), consistent with 2 also being a weak inhibitor of cellular IPMK (Table 1), which synthesizes InsP $\mathrm{P}_{5}$ from $\mathrm{InsP}_{3}$ 23,44 . These data are consistent with our hypothesis (see above) that, in intact cells, the flavonoids used in our study will preferentially inhibit IP6K activity over IPMK activity.

We next obtained time course data, using $2.5 \mu \mathrm{M}$ levels of $\mathbf{2}$, which are sufficient to reduce $\mathrm{InsP}_{7}$ levels by $50-70 \%$ (Fig. 6B), without significantly impacting cellular synthesis of either $\mathrm{InsP}_{5}$ or $\mathrm{InsP}_{6}$ (Fig. 6C). The diminution in cellular $\mathrm{InsP}_{7}$ content was greatest after 
30 min of treatment; a slight restoration of $\mathrm{InsP}_{7}$ levels was observed thereafter, perhaps due to some cellular metabolism of $2^{45}$. We also performed a time-course analysis for the effects of 3 and 7 upon intact cells, again at concentrations of $2.5 \mu \mathrm{M}$. We found that 7 produced the most sustained inhibition of $\mathrm{InsP}_{7}$ synthesis (Fig. 6B). Moreover, 7 had no effect upon $\mathrm{InsP}_{5}$ (Fig. 6C), and also did not significantly alter InsP $\mathrm{P}_{6}$ levels (Fig. 6D). The degree of inhibition of $\mathrm{InsP}_{7}$ synthesis by $\mathbf{7}$ was slightly stronger and more sustained than that of either $\mathbf{2}$ or $\mathbf{3}$ (Fig. 6B). These demonstrations that flavonoids inhibit IP6K activity in intact cells serve as an orthogonal validation of the data obtained in vitro with recombinant enzyme (Table 1).

We also determined cellular levels of $\operatorname{InsP}_{5}, \mathrm{InsP}_{6}$ and $\mathrm{InsP}_{7}$ after $3.5 \mathrm{hr}$ treatment with 2.5 $\mu \mathrm{M}$ concentrations of $\mathbf{1}, \mathbf{4}, \mathbf{6}$ and $\mathbf{1 1}$, which together with $\mathbf{2 , 3}$ and $\mathbf{7}$ comprise our seven strongest IP6K inhibitors (Table 1). Levels of InsP $\mathrm{P}_{5}$ and $\mathrm{InsP}_{6}$ were not significantly affected (Fig. 7A,B), and all but 11 inhibited InsP $_{7}$ synthesis to varying degrees levels (Fig. 7C).

The inability of $\mathbf{1 1}$ to reduce $\mathrm{InsP}_{7}$ in HCT116 cells (Fig. 7C) may reflect it being the weakest of the IP6K inhibitors that we used in this experiment (see Table 1). In addition, 11 might be more rapidly inactivated by its metabolism and/or less efficiently accumulated from the culture medium. As for $\mathbf{1}$, which only slightly altered $\mathrm{Ins}_{7}$ levels, its greater degree of hydroxylation (i.e., lower hydrophobicity) may hinder its permeation through the cell membrane. Nevertheless, it is clear from our data (Table 1; Fig. 7A,B,C), that a range of flavonoids are effective inhibitors of IP6K activity in intact HCT116 cells. Among these flavonoids, 7 emerged as the most effective inhibitor of $\operatorname{InsP}_{7}$ levels.

It is significant that the concentration of $\mathbf{2}$ that we used in these experiments $(2.5 \mu \mathrm{M})$ is equivalent to that recorded in the human small intestine and colon ${ }^{45,50}$, reflecting it being one of the most abundant flavonoids in the human diet ${ }^{46}$; dietary supplementation would raise the concentration further. Thus, we conclude that IP6K in cells that line the gastrointestinal tract should be considered as a biologically-relevant target of dietary flavonoids.

We have also analyzed the effects of $\mathbf{2 , 3}$ and $\mathbf{7}$ in HEK293 cells (Fig. 8A,B,C). We found that all three flavonoids reduced $\mathrm{InsP}_{7}$ levels, indicating IP6K activity was inhibited in these cells; levels of InsP $\mathrm{P}_{5}$ and $\mathrm{InsP}_{6}$ were not affected.

\section{The effects of flavonoids upon AKT activity in intact cells.}

Flavonoids such as $\mathbf{2}$ have been shown to inhibit PI3K activity in vitro ${ }^{25}$, and that effect is proposed to underlie the inhibition of the downstream protein kinase AKT that has been observed in some cell types following their treatment with flavonoids ${ }^{28-29,51-52}$. However, the alternate possibility that AKT may in some cases be activated by flavonoids, is raised by our demonstration that this group of molecules inhibit IP6K activity in intact cells (Fig. 7,8), since the $\mathrm{InsP}_{7}$ product of IP6K activity is an inhibitor AKT ${ }^{3,18,53}$. Indeed, in some cell types, inhibition of IP6K activity by TNP is accompanied by activation of AKT ${ }^{3}, 18,53$.

We used two different cell types to study the net effect of these potentially competing influences of flavonoids upon AKT activity. In HCT116 cells, we did not observe any statistically-significant effect upon AKT activity following treatment with $2.5 \mu \mathrm{M}$ 
concentrations of either $\mathbf{2}, \mathbf{3}$ or $\mathbf{7}$ (Fig. 9A), which is sufficient to strongly inhibit cellular IP6K activity (Fig. 7,8). In control experiments, inhibition of IP6K by TNP also did not affect AKT activity in HCT116 cells (Fig. 9A). On the other hand, AKT activity increased following TNP treatment of 3T3-L1 preadipocytes (Fig. 9B); similar data were previously reported following TNP addition to adipocytes ${ }^{18}$. We also found AKT activity to be increased upon treatment of 3T3-L1 cells with $2.5 \mu \mathrm{M}$ concentrations of either $\mathbf{2 , 3}$ or 7 (Fig. 9B). Our data (Fig. 9A,B) indicate that the nature of the impact of flavonoids upon AKT signaling pathways will be determined by multiple inputs that vary depending upon the cell type.

In conclusion, our detailed structure/activity data, which include new crystal structures of hIPMK in complex with various flavonoids, together improve insight into the pharmacophore space within the ATP-binding pocket of InsPKs, which may accelerate the design of InsPK inhibitors. Finally, our data suggest that dietary flavonoids may inhibit IP6K activity in cells that line the gastrointestinal tract, which opens up a new area of focus for those studying the human health significance of flavonoids as dietary supplements.

\section{EXPERIMENTAL PROCEDURES}

\section{Protein expression and purification.}

Recombinant hIP6K2 and hIPMK were prepared as previously described ${ }^{23-24}$.The purity of these proteins was estimated to be $>90 \%$ as judged by SDS-PAGE. The purified proteins were concentrated to between 1 and $2 \mathrm{mg} / \mathrm{ml}$ and stored at $-80^{\circ} \mathrm{C}$.

Compound IC $_{50}$ determination for inhibition of hIP6K2 and hIPMK.-ATP-driven kinase activity was measured by detecting ADP formation from substrate phosphorylation using the Adapta ${ }^{\mathrm{TM}}$ Universal Kinase Assay. Dilution plates of selected flavonoids (Fig. 1) were made using a Freedom EVO liquid handler (Tecan) (3-fold dilutions, 10 points, at 100x), using DMSO as diluent into 384-well plates. Compounds were subsequently dispensed using a Mosquito (TTP Labtech) to deliver 50nl into assay plates to give a 10point dose response with the following concentrations (all $\mu \mathrm{M}$ ): 0.005, 0.015, 0.046, 0.14, $0.41,1.23,3.7,11.1,33.3,100$. The final DMSO concentration $=1 \%$.

The Adapta ${ }^{\mathrm{TM}}$ kinase reaction buffer was used to prepare all additions; it contained $50 \mathrm{mM}$ HEPES pH 7.5, 0.01\% Brij-35, $10 \mathrm{mM} \mathrm{MgCl}_{2}$, and 1 mM EGTA. A Multidrop Combi Reagent Dispenser (ThermoFisher) was used to dispense $2.5 \mu \mathrm{L}$ of $(2 \mathrm{x})$ kinase to the assay plates (to final concentrations of $400 \mathrm{nM}$ for hIP6K2 and $12 \mathrm{nM}$ for hIPMK). After a $15 \mathrm{~min}$ equilibration period at room temperature, $2.5 \mu \mathrm{L}$ of $(2 \mathrm{x}) \mathrm{ATP} /$ substrate mix was added to final concentrations of either $10 \mu \mathrm{M}$ ATP and $10 \mu \mathrm{M}$ InsP $_{6}$ (IP6K assays) or $10 \mu \mathrm{M}$ ATP and $10 \mu \mathrm{M} \mathrm{InsP} \mathrm{P}_{3}$ (for IPMK assays). Reaction conditions were selected such that displacement of the ADP tracer from the antibody was $70-80 \%$ (according to the vendor's guidelines). The enzymatic reaction was performed for $30 \mathrm{~min}$ and the amount of ADP produced was detected by adding $2.5 \mu \mathrm{L}$ of detection solution Adapta ${ }^{\mathrm{TM}}$ Eu-anti-ADP antibody, Alexa Fluor $^{\circledR} 647$ ADP tracer, and EDTA, for a final concentration of $2 \mathrm{nM}, 12 \mathrm{nM}$, and $10 \mathrm{mM}$ respectively (using the provided TR-FRET Dilution Buffer). After an additional $30 \mathrm{~min}$ equilibration period, the plate was read on an EnVision (PerkinElmer) plate reader 
(excitation $=320 \mathrm{~nm}$, emission $=665 \mathrm{~nm}$ and $615 \mathrm{~nm}$ ). The HTRF signal was calculated as a ratio of the signals from the $665 \mathrm{~nm}$ (acceptor) and $615 \mathrm{~nm}$ (donor) channels. For each plate, percent inhibition was calculated relative to the interquartile mean of 16 wells each of positive controls (DMSO alone) and negative controls (no enzyme added). ADP titration curves were also run routinely, to assure that the enzyme assays produced approx. 20\% ATP turnover. $\mathrm{IC}_{50}$ values were generally calculated by applying a 4-parameter curve fit using ScreenAble Solutions.

\section{Structural studies.}

Crystals of apo-hIPMK were prepared as described previously ${ }^{23}$. Complex crystals were produced by soaking apo crystals into a mixture of 2-10 mM compounds with $35 \%(\mathrm{w} / \mathrm{v})$ PEG 400, $0.1 \mathrm{M} \mathrm{Li}_{2} \mathrm{SO}_{4}, 100 \mathrm{mM}$ HEPES (pH 7.5) at $25^{\circ} \mathrm{C}$ for 3 days. Diffraction data were collected using APS beamlines 22-ID and 22-BM. All data were processed with the program HKL2000 ${ }^{54}$. The crystal structures were determined by using rigid body and direct Fourier synthesis, and refined with the equivalent and expanded test sets by using programs in the CCP4 package ${ }^{55-56}$. The molecular graphics representations were prepared with the program PyMol (Schrödinger, LLC). Atomic coordinates and structure factors for hIPMK/ flavonoid complexes have been deposited with the Protein Data Bank with the following accession codes (with ligands in parentheses): 6M88 (1), 6M89 (2), 6M8A (3), 6M8B (4), 6M8C (6), 6M8D (7), 6M8E (11). All structural refinement data are shown in Supplementary Table 1 . The structure of hIP6K2 was modeled as previously described ${ }^{24}$, and 2 was docked into the structure by superimposing the hIPMK/2 complex structure on the calculated hIP6K2 model.

\section{Cell culture, and assay of intracellular inositol phosphates.}

The 3T3-L1 fibroblasts were cultured in 6-well plates in DMEM+ media. The culture conditions for HEK293 cells and HCT116 cells, and conditions for $\left[{ }^{3} \mathrm{H}\right]$ inositol-labeling, are as described previously ${ }^{57}$, except that the concentration of $\left[{ }^{3} \mathrm{H}\right]$ inositol was increased to 20 $\mu \mathrm{Ci} / \mathrm{ml}$. Added flavonoids were dissolved in DMSO; the final concentration of DMSO in the cell cultures (and DMSO vehicle controls) was $0.1 \%$. Cells were PCA-quenched, and $\left[{ }^{3} \mathrm{H}\right]$ InsPs were extracted and assayed by CarboPac HPLC, as previously described ${ }^{57}$. Statistical significance of each sample, versus DMSO control, was evaluated by one-way ANOVA (Dunnett's Method).

\section{AKT activity assays.}

We studied AKT activity in either 2-day, post-confluent 3T3-L1 preadipocytes, or 1-day post confluent HCT116 cells. These cells were treated for $3 \mathrm{~h}$ with either DMSO vehicle control or $2.5 \mu \mathrm{M}$ of the indicated flavonoid (in DMSO) or $1 \mu \mathrm{M}$ TNP (for 3T3-L1 cells) or $10 \mu \mathrm{M}$ TNP (for HCT116 cells), also in DMSO. In each case, the final DMSO concentration was $0.1 \%$. Thereafter, each well of cells was washed with ice-cold PBS and lysed in $200 \mu \mathrm{l}$ of ice-cold buffer containing $50 \mathrm{mM}$ Tris- $\mathrm{HCl}(\mathrm{pH} 7.4), 150 \mathrm{mM} \mathrm{NaCl}, 1 \%$ Triton X-100 and a protease-phosphatase inhibitor tablet (Pierce; \# A32961) The lysate was cleared by centrifugation $\left(16,000 \mathrm{xg}\right.$ for $\left.20 \mathrm{~min} ; 4^{\circ} \mathrm{C}\right)$, and then protein concentrations were assayed with a BCA kit. A total of $20 \mu \mathrm{g}$ protein per sample was resolved by SDS-PAGE gel, 
transferred to either a nitrocellulose or PVDF membrane, and probed with antibodies for both phospho-AKT (T308; Cell Signaling \#13038; dilution: 1:1000) and total AKT (either Santa Cruz, sc-81434 or Cell Signaling \#9272; dilution: 1:1000). Band intensities were quantified using the ImageJ software. The intensity of each phospho-AKT band was calculated relative to total AKT, and those resultant ratios were then normalized to the sum of all ratios obtained from a single gel ${ }^{58}$. Statistical significance of each sample, versus DMSO control, was evaluated by one-way ANOVA (Dunnett's Method).

\section{Other Reagents.}

Compounds 1-8, 11 were purchased from Cayman Chemical; 9-10, 12-17 were obtained from Indofine Chemical. $\left[{ }^{3} \mathrm{H}\right]$ inositol was purchased from American Radiolabeled Chemicals. InsP $\mathrm{P}_{3}$ was purchased from CellSignals. InsP $\mathrm{P}_{6}$ was procured from Calbiochem. The Adapta ${ }^{\mathrm{TM}}$ Universal Kinase Assay kits were obtained from Thermo Fisher.

\section{Supplementary Material}

Refer to Web version on PubMed Central for supplementary material.

\section{ACKNOWLEDGEMENTS}

C.G., H.W., and S.B.S are supported by the Intramural Research Program of the NIH, National Institutes of Environmental Health Sciences. The National Institutes of Health is also thanked for its support of A.C. (NIH-R01 DK103746) and K.H.P. (NIH-R01 DK101645). We are grateful to the NIEHS Collaborative crystallography group, and the Advanced Photon Source (APS) SE Regional Collaborative Access Team (SER-CAT) 22-ID and 22-BM beam lines, for assistance with crystallographic data collection. We thank Dr. Daowei Huang for help with compound handling.

\section{ABBREVIATIONS USED.}

$\begin{array}{ll}\text { DMSO } & \text { dimethylsulfoxide } \\ \text { hIP6K } & \text { human inositol hexakisphosphate kinase } \\ \text { hIPMK } & \text { human inositol polyphosphate multikinase } \\ \text { InsP } & \text { inositol phosphate } \\ \text { InsP3 } & \text { inositol 1,4,5 trisphosphate } \\ \text { InsP }_{5} & \text { inositol-1,3,4,5,6-pentakisphosphate } \\ \text { InsP } & \text { inositol hexakisphophate } \\ \text { InsP } & \text { diphospho-inositol-1,2,3,4,6-pentakisphosphate } \\ \text { PBS } & \text { phosphate-buffered saline } \\ \text { TNP } & N 2 \text {-( } m \text {-(trifluoromethyl)benzyl) } N 6 \text {-( } p \text {-nitrobenzyl)purine } \\ \text { TR-FRET } & \text { time-resolved fluorescence resonance energy transfer }\end{array}$




\section{REFERENCES}

1. Irvine RF; Schell M, Back in the Water: The Return of the Inositol Phosphates. Nature Reviews Molecular Cell Biology 2001, 2, 327-338. [PubMed: 11331907]

2. Kim E; Ahn H; Kim MG; Lee H; Kim S, The Expanding Significance of Inositol Polyphosphate Multikinase as a Signaling Hub. Mol. Cells 2017, 40 (5), 315-321. [PubMed: 28554203]

3. Chakraborty A, The Inositol Pyrophosphate Pathway in Health and Diseases. Biol. Rev. Camb. Philos. Soc 2017, 93, 1203-1227. [PubMed: 29282838]

4. Hatch AJ; York JD, Snapshot: Inositol Phosphates. Cell 2010, 143 (6), 1030-1030. [PubMed: 21145466]

5. Gu C; Nguyen HN; Ganini D; Chen Z; Jessen HJ; Gu Z; Wang H; Shears SB, Ko of 5-Insp7 Kinase Activity Transforms the HCT116 Colon Cancer Cell Line into a Hypermetabolic, Growth-Inhibited Phenotype. Proc. Natl. Acad. Sci. U. S. A 2017, 114, 11968-11973. [PubMed: 29078269]

6. Padmanabhan U; Dollins DE; Fridy PC; York JD; Downes CP, Characterization of a Selective Inhibitor of Inositol Hexakisphosphate Kinases: Use in Defining Biological Roles and Metabolic Relationships of Inositol Pyrophosphates. J. Biol. Chem 2009, 284, 10571-10582. [PubMed: 19208622]

7. Puhl-Rubio AC; Stashko MA; Wang H; Hardy PB; Tyagi V; Li B; Wang X; Kireev D; Jessen HJ; Frye SV; Shears SB; Pearce KH, Use of Protein Kinase-Focused Compound Libraries for the Discovery of New Inositol Phosphate Kinase Inhibitors. SLAS. Discov 2018, 2472555218775323.

8. Wormald M; Liao G; Kimos M; Barrow J; Wei H, Development of a Homogenous High-Throughput Assay for Inositol Hexakisphosphate Kinase 1 Activity. PLoS. ONE 2017, 12 (11), e0188852. [PubMed: 29186181]

9. Schroder D; Todter K; Gonzalez B; Franco-Echevarria E; Rohaly G; Blecher C; Lin HY; Mayr GW; Windhorst $\mathrm{S}$, The New InsP3 kinase Inhibitor Bip-4 Is Competitive to InsP3 and Blocks Proliferation and Adhesion of Lung Cancer Cells. Biochem Pharmacol 2015, 96 (2), 143-150. [PubMed: 25986882]

10. Saiardi A; Erdjument-Bromage H; Snowman A; Tempst P; Snyder SH, Synthesis of Diphosphoinositol Pentakisphosphate by a Newly Identified Family of Higher Inositol Polyphosphate Kinases. Curr. Biol 1999, 9, 1323-1326. [PubMed: 10574768]

11. Bhandari R; Saiardi A; Ahmadibeni Y; Snowman AM; Resnick AC; Kristiansen TZ; Molina H; Pandey A; Werner JK Jr.; Juluri KR; Xu Y; Prestwich GD; Parang K; Snyder SH, Protein Pyrophosphorylation by Inositol Pyrophosphates Is a Posttranslational Event. Proc. Natl. Acad. Sci. U. S. A 2007, 104, 15305-15310. [PubMed: 17873058]

12. Shears SB, Intimate Connections: Inositol Pyrophosphates at the Interface of Metabolic Regulation and Cell-Signaling. J. Cell Physiol 2017, 233, 1897-1912. [PubMed: 28542902]

13. Gao Y; Wang HY, Inositol Pentakisphosphate Mediates Wnt/Beta-Catenin Signaling. J. Biol. Chem 2007, 282 (36), 26490-26502. [PubMed: 17595165]

14. Kim E; Beon J; Lee S; Park J; Kim S, Ipmk: A Versatile Regulator of Nuclear Signaling Events. Adv. Biol. Regul 2015, 61, 25-32. [PubMed: 26682649]

15. Saiardi A; Azevedo C; Desfougeres Y; Portela-Torres P; Wilson MSC, Microbial Inositol Polyphosphate Metabolic Pathway as Drug Development Target. Adv. Biol. Regul 2018, 67, 74 83. [PubMed: 28964726]

16. Cestari I; Haas P; Moretti NS; Schenkman S; Stuart K, Chemogenetic Characterization of Inositol Phosphate Metabolic Pathway Reveals Druggable Enzymes for Targeting Kinetoplastid Parasites. Cell Chem. Biol 2016, 23 (5), 608-617. [PubMed: 27133314]

17. Windhorst S; Song K; Gazdar AF, Inositol-1,4,5-Trisphosphate 3-Kinase-a (Itpka) Is Frequently over-Expressed and Functions as an Oncogene in Several Tumor Types. Biochem Pharmacol 2017, 137, 1-9. [PubMed: 28377279]

18. Ghoshal S; Zhu Q; Asteian A; Lin H; Xu H; Ernst G; Barrow JC; Xu B; Cameron MD; Kamenecka TM; Chakraborty A, Tnp [N2-(M-Trifluorobenzyl), N6-(P-Nitrobenzyl)Purine] Ameliorates Diet Induced Obesity and Insulin Resistance Via Inhibition of the IP6K1 Pathway. Molecular Metabolism 2016, 5, 903-917. [PubMed: 27689003] 
19. Chang YT; Choi G; Bae YS; Burdett M; Moon HS; Lee JW; Gray NS; Schultz PG; Meijer L; Chung SK; Choi KY; Suh PG; Ryu SH, Purine-Based Inhibitors of Inositol-1,4,5-Trisphosphate-3Kinase. Chembiochem 2002, 3 (9), 897-901. [PubMed: 12210991]

20. Sekar MC; Shahiwala K; Leloup L; Wells A, Modulation of Epidermal Growth Factor Stimulated Erk Phosphorylation and Cell Motility by Inositol Trisphosphate Kinase. J. Pharm. Sci. Pharmacol 2014, 1 (2), 160-164. [PubMed: 26213696]

21. Eva R; Bouyoucef-Cherchalli D; Patel K; Cullen PJ; Banting G, IP3 3-Kinase Opposes Ngf Driven Neurite Outgrowth. PLoS. ONE 2012, 7 (2), e32386. [PubMed: 22384237]

22. Shears SB; Wang H, Inositol Phosphate Kinases: Expanding the Biological Significance of the Universal Core of the Protein Kinase Fold. Advances in Biological Regulation 2018, doi: 10.1016/ j.jbior.2018.10.006.

23. Wang H; Shears SB, Structural Features of Human Inositol Phosphate Multikinase Rationalize Its Inositol Phosphate Kinase and Phosphoinositide 3-Kinase Activities. J. Biol. Chem 2017, 292, 18192-18202. [PubMed: 28882892]

24. Wang H; DeRose EF; London RE; Shears SB, Ip6k Structure and the Molecular Determinants of Catalytic Specificity in an Inositol Phosphate Kinase Family. Nature Communications 2014, 5:4178, doi: 10.1038/ncomms5178.

25. Walker EH; Pacold ME; Perisic O; Stephens L; Hawkins PT; Wymann MP; Williams RL, Structural Determinants of Phosphoinositide 3-Kinase Inhibition by Wortmannin, LY294002, Quercetin, Myricetin, and Staurosporine. Mol. Cell 2000, 6 (4), 909-919. [PubMed: 11090628]

26. Navarro-Retamal C; Caballero J, Flavonoids as Cdk1 Inhibitors: Insights in Their Binding Orientations and Structure-Activity Relationship. PLoS One 2016, 11 (8), e0161111. [PubMed: 27517610]

27. Wright B; Spencer JP; Lovegrove JA; Gibbins JM, Insights into Dietary Flavonoids as Molecular Templates for the Design of Anti-Platelet Drugs. Cardiovasc Res 2013, 97 (1), 13-22. [PubMed: 23024269]

28. Russo M; Milito A; Spagnuolo C; Carbone V; Rosen A; Minasi P; Lauria F; Russo GL, Ck2 and PI3K Are Direct Molecular Targets of Quercetin in Chronic Lymphocytic Leukaemia. Oncotarget 2017, 8 (26), 42571-42587. [PubMed: 28489572]

29. Nanua S; Zick SM; Andrade JE; Sajjan US; Burgess JR; Lukacs NW; Hershenson MB, Quercetin Blocks Airway Epithelial Cell Chemokine Expression. Am J Respir Cell Mol Biol 2006, 35 (5), 602-610. [PubMed: 16794257]

30. Gledhill JR; Montgomery MG; Leslie AG; Walker JE, Mechanism of Inhibition of Bovine F1Atpase by Resveratrol and Related Polyphenols. Proc Natl Acad Sci U S A 2007, 104 (34), 13632-13637. [PubMed: 17698806]

31. Cao H; Pauff JM; Hille R, X-Ray Crystal Structure of a Xanthine Oxidase Complex with the Flavonoid Inhibitor Quercetin. J Nat Prod 2014, 77 (7), 1693-1699. [PubMed: 25060641]

32. Xue G; Gong L; Yuan C; Xu M; Wang X; Jiang L; Huang M, A Structural Mechanism of Flavonoids in Inhibiting Serine Proteases. Food Funct 2017, 8 (7), 2437-2443. [PubMed: 28644504]

33. Tawani A; Kumar A, Structural Insight into the Interaction of Flavonoids with Human Telomeric Sequence. Scientific Reports 2015, 5, 17574. [PubMed: 26627543]

34. Fang Y; Liang F; Liu K; Qaiser S; Pan S; Xu X, Structure Characteristics for Intestinal Uptake of Flavonoids in Caco-2 Cells. Food Res Int 2018, 105, 353-360. [PubMed: 29433224]

35. Aldrich C; Bertozzi C; Georg GI; Kiessling L; Lindsley C; Liotta D; Merz KM Jr.; Schepartz A; Wang S, The Ecstasy and Agony of Assay Interference Compounds. ACS Infect Dis 2017, 3 (4), 259-262. [PubMed: 28244723]

36. Baell JB; Holloway GA, New Substructure Filters for Removal of Pan Assay Interference Compounds (Pains) from Screening Libraries and for Their Exclusion in Bioassays. Journal of Medicinal Chemistry 2010, 53 (7), 2719-2740. [PubMed: 20131845]

37. Bustos AS; Hakansson A; Linares-Pasten JA; Penarrieta JM; Nilsson L, Interaction between Phenolic Compounds and Lipase: The Influence of Solubility and Presence of Particles in the Ic50 Value. J Food Sci 2018, 83 (8), 2071-2076. [PubMed: 30020550] 
38. Bennett M; Onnebo SM; Azevedo C; Saiardi A, Inositol Pyrophosphates: Metabolism and Signaling. Cell. Mol. Life Sci 2006, 63, 552-564. [PubMed: 16429326]

39. Huggins DJ; Sherman W; Tidor B, Rational Approaches to Improving Selectivity in Drug Design. J Med Chem 2012, 55 (4), 1424-1444. [PubMed: 22239221]

40. Jeffrey GA, An Introduction to Hydrogen Bonding Oxford University Press: New York, 1997.

41. Yokoyama T; Kosaka Y; Mizuguchi M, Structural Insight into the Interactions between DeathAssociated Protein Kinase 1 and Natural Flavonoids. J. Med. Chem 2015, 58 (18), 7400-7408. [PubMed: 26322379]

42. Sicheri F; Moarefi I; Kuriyan J, Crystal Structure of the Src Family Tyrosine Kinase Hck. Nature 1997, 385 (6617), 602-609. [PubMed: 9024658]

43. Kolozsvari B; Parisi F; Saiardi A, Inositol Phosphates Induce DAPI Fluorescence Shift. Biochem. J 2014, 460 (3), 377-385. [PubMed: 24670057]

44. Saiardi A; Caffrey JJ; Snyder SH; Shears SB, Inositol Polyphosphate Multikinase (Argriii)

Determines Nuclear Mrna Export in Saccharomyces Cerevisiae. FEBS Lett 2000, 468, 28-32. [PubMed: 10683435]

45. Chen Z; Zheng S; Li L; Jiang H, Metabolism of Flavonoids in Human: A Comprehensive Review. Curr Drug Metab 2014, 15 (1), 48-61. [PubMed: 24588554]

46. Darband SG; Kaviani M; Yousefi B; Sadighparvar S; Pakdel FG; Attari JA; Mohebbi I; Naderi S; Majidinia M, Quercetin: A Functional Dietary Flavonoid with Potential Chemo-Preventive Properties in Colorectal Cancer. J. Cell Physiol 2018, 233 (9), 6544-6560. [PubMed: 29663361]

47. Koldobskiy MA; Chakraborty A; Werner JK Jr.; Snowman AM; Juluri KR; Vandiver MS; Kim S; Heletz S; Snyder SH, P53-Mediated Apoptosis Requires Inositol Hexakisphosphate Kinase-2. Proc. Natl. Acad. Sci. U. S. A 2010, 107, 20947-20951. [PubMed: 21078964]

48. Sanver D; Murray BS; Sadeghpour A; Rappolt M; Nelson AL, Experimental Modeling of Flavonoid-Biomembrane Interactions. Langmuir 2016, 32 (49), 13234-13243. [PubMed: 27951697]

49. Egert S; Wolffram S; Bosy-Westphal A; Boesch-Saadatmandi C; Wagner AE; Frank J; Rimbach G; Mueller MJ, Daily Quercetin Supplementation Dose-Dependently Increases Plasma Quercetin Concentrations in Healthy Humans. J. Nutr 2008, 138 (9), 1615-1621. [PubMed: 18716159]

50. Jenner AM; Rafter J; Halliwell B, Human Fecal Water Content of Phenolics: The Extent of Colonic Exposure to Aromatic Compounds. Free Radic Biol Med 2005, 38 (6), 763-772. [PubMed: 15721987]

51. Kittl M; Beyreis M; Tumurkhuu M; Furst J; Helm K; Pitschmann A; Gaisberger M; Glasl S; Ritter M; Jakab M, Quercetin Stimulates Insulin Secretion and Reduces the Viability of Rat Ins-1 BetaCells. Cell Physiol Biochem 2016, 39 (1), 278-293. [PubMed: 27336168]

52. Spencer JP; Rice-Evans C; Williams RJ, Modulation of Pro-Survival Akt/Protein Kinase B and Erk1/2 Signaling Cascades by Quercetin and Its in Vivo Metabolites Underlie Their Action on Neuronal Viability. J. Biol. Chem 2003, 278 (37), 34783-34793. [PubMed: 12826665]

53. Chakraborty A; Koldobskiy MA; Bello NT; Maxwell M; Potter JJ; Juluri KR; Maag D; Kim S; Huang AS; Dailey MJ; Saleh M; Snowman AM; Moran TH; Mezey E; Snyder SH, Inositol Pyrophosphates Inhibit Akt Signaling, Thereby Regulating Insulin Sensitivity and Weight Gain. Cell 2010, 143 (6), 897-910. [PubMed: 21145457]

54. Otwinowski Z; Minor W, Processing of X-Ray Diffraction Data Collected in Oscillation Mode. Methods Enzymol 1997, 276, 307-326.

55. Emsley P; Cowtan K, Coot: Model-Building Tools for Molecular Graphics. Acta Crystallogr. D. Biol. Crystallogr 2004, 60 (Pt 12 Pt 1), 2126-2132. [PubMed: 15572765]

56. Winn MD; Murshudov GN; Papiz MZ, Macromolecular Tls Refinement in Refmac at Moderate Resolutions. Methods Enzymol 2003, 374, 300-321. [PubMed: 14696379]

57. Gu C; Nguyen HN; Hofer A; Jessen HJ; Dai X; Wang H; Shears SB, The Significance of the Bifunctional Kinase/Phosphatase Activities of Ppip5ks for Coupling Inositol Pyrophosphate CellSignaling to Cellular Phosphate Homeostasis. J. Biol. Chem 2017, 292, 4544-4555. [PubMed: 28126903] 
58. Degasperi A; Birtwistle MR; Volinsky N; Rauch J; Kolch W; Kholodenko BN, Evaluating Strategies to Normalise Biological Replicates of Western Blot Data. PLoS. ONE 2014, 9 (1), e87293. [PubMed: 24475266] 

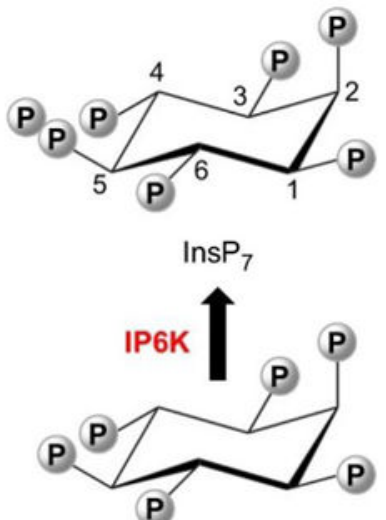

(P)

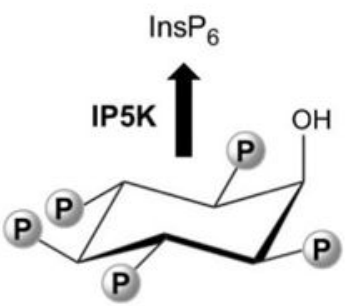

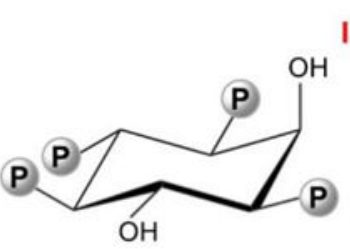

$\operatorname{lns}(1,3,4,5) \mathrm{P}_{4}$

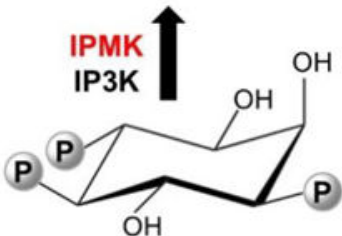

$\operatorname{lns}(1,4,5) \mathrm{P}_{3}$

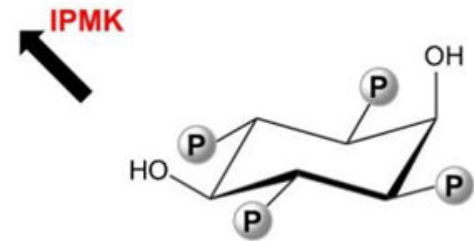

$\operatorname{lns}(1,3,4,6) P_{3}$

INPP5

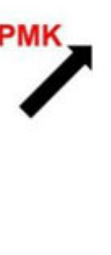



Fig. 1. The roles of IPMK and IP6K in the mammalian InsP metabolic pathway. 'Ins' refers to inositol; the subscripts denote the total number of phosphates ('P'), and the numbers in parentheses describe the positions of the phosphate groups around the inositol ring. Arrows depict metabolic steps, catalyzed by the following enzymes: IP3K, inositol trisphosphate 3-kinase; IPMK, inositol polyphosphate multikinase; INPP5, inositol polyphosphate 5-phosphatase; ITPK1, inositol trisphosphate 6-kinase/ inositol tetrakisphosphate 1-kinase; IP5K, inositol pentakisphosphate 2-kinase; IP6K, inositol hexakisphosphate kinase. The enzymes that are the focus of this study - IPMK and IP6K are highlighted in red font. 

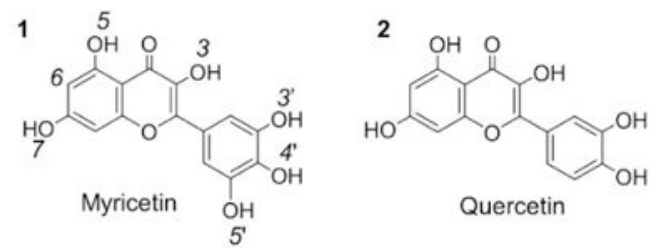

3

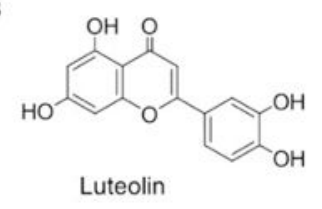

7

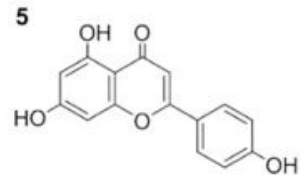

Apigenin

9

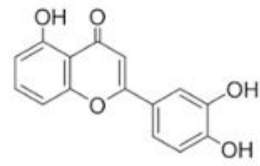

5,3',4'-Trihydroxyflavone
6

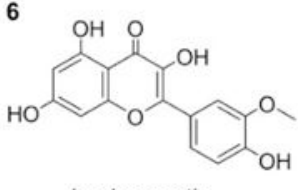

Isorhamnetin

10

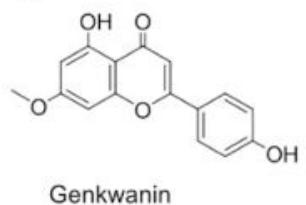

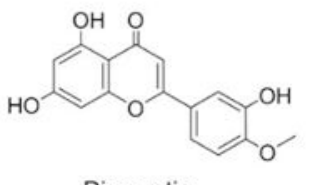

11

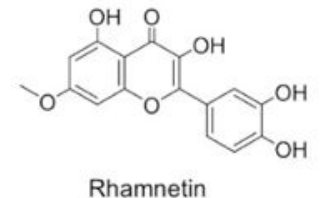

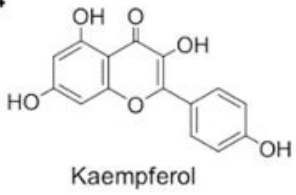

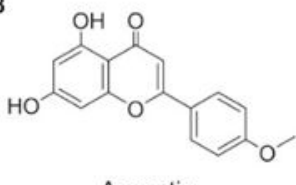

12

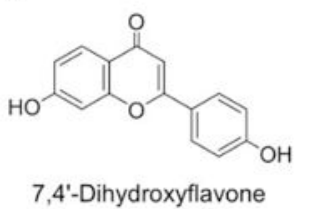

13

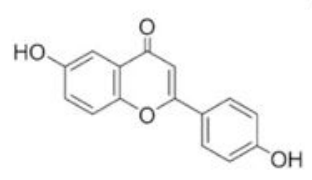

6,4'-Dihydroxyflavone

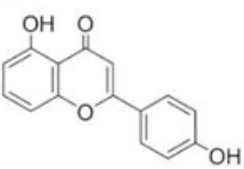

5,4'-Dihydroxyflavone
15

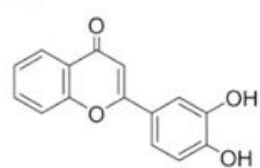

3',4'-Dihydroxyflavone
16<smiles>O=C1C[C@H](c2ccc(O)c(O)c2)Oc2cc(O)cc(O)c21</smiles>

Eriodictyol
17

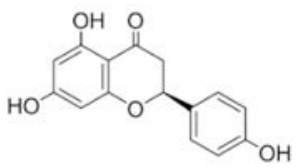

Fig. 2. Chemical structures of the flavonoids used in this study 

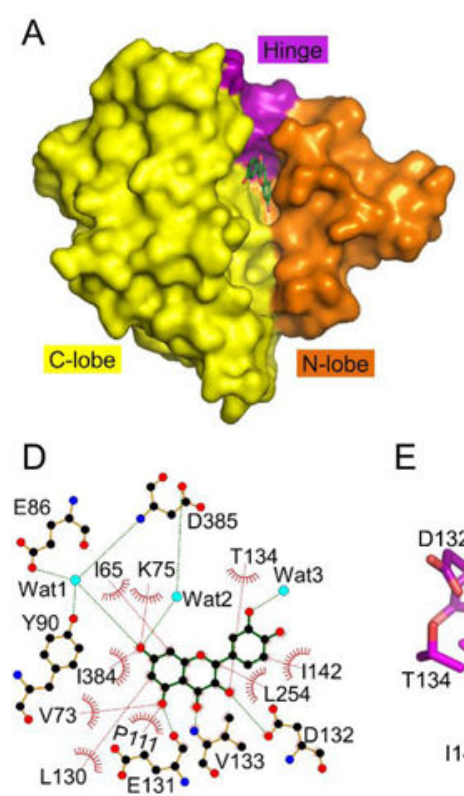

$E$
B

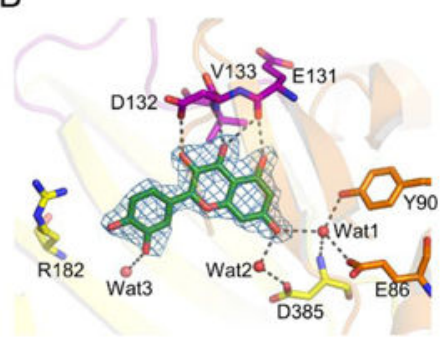

C

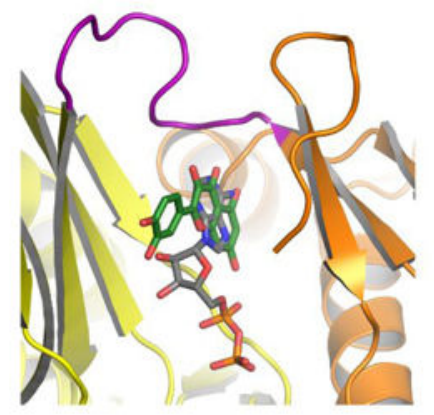

$\mathrm{F}$

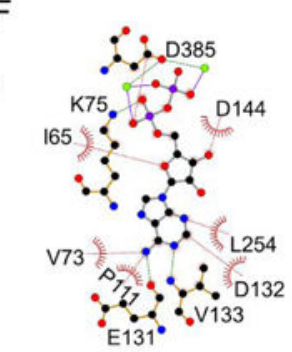

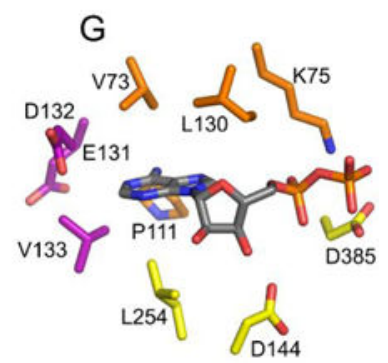

Fig. 3. Structure of the hIPMK/2 crystal complex.

A, Surface representation of quercetin binding. The $\mathrm{C}$ - and $\mathrm{N}$-lobes are depicted in yellow and orange, respectively; the hinge region (E131 to K139 ${ }^{23}$ ) is colored purple, and $\mathbf{2}$ is shown as a dark green stick model, with the oxygen atoms illustrated in red. All color coding is retained for structural elements shown in the other panels. B, Polar interactions of $\mathbf{2}$ with hIPMK; 2Fo-Fc electron density maps (skyblue mesh) are contoured at $1.0 \sigma$. Hydrogen bonds are shown in broken gray lines. Water molecules that directly interact with $\mathbf{2}$ are depicted as red spheres. C, Ribbon plot of hIPMK showing superimposition of bound $\mathbf{2}$ (this study, $\mathrm{PDB}=6 \mathrm{M} 89$ ) and $\mathrm{ADP}$ (from ${ }^{23}, \mathrm{PDB}=5 \mathrm{~W} 2 \mathrm{H}$; dark gray stick model; nitrogen atoms are shown in blue). D-G show ligplots and relative spatial positioning of all residues which make either Van der Waals or polar interactions with either $2(\mathbf{D}, \mathbf{E})$ or ADP $(\mathbf{F}, \mathbf{G})$. 

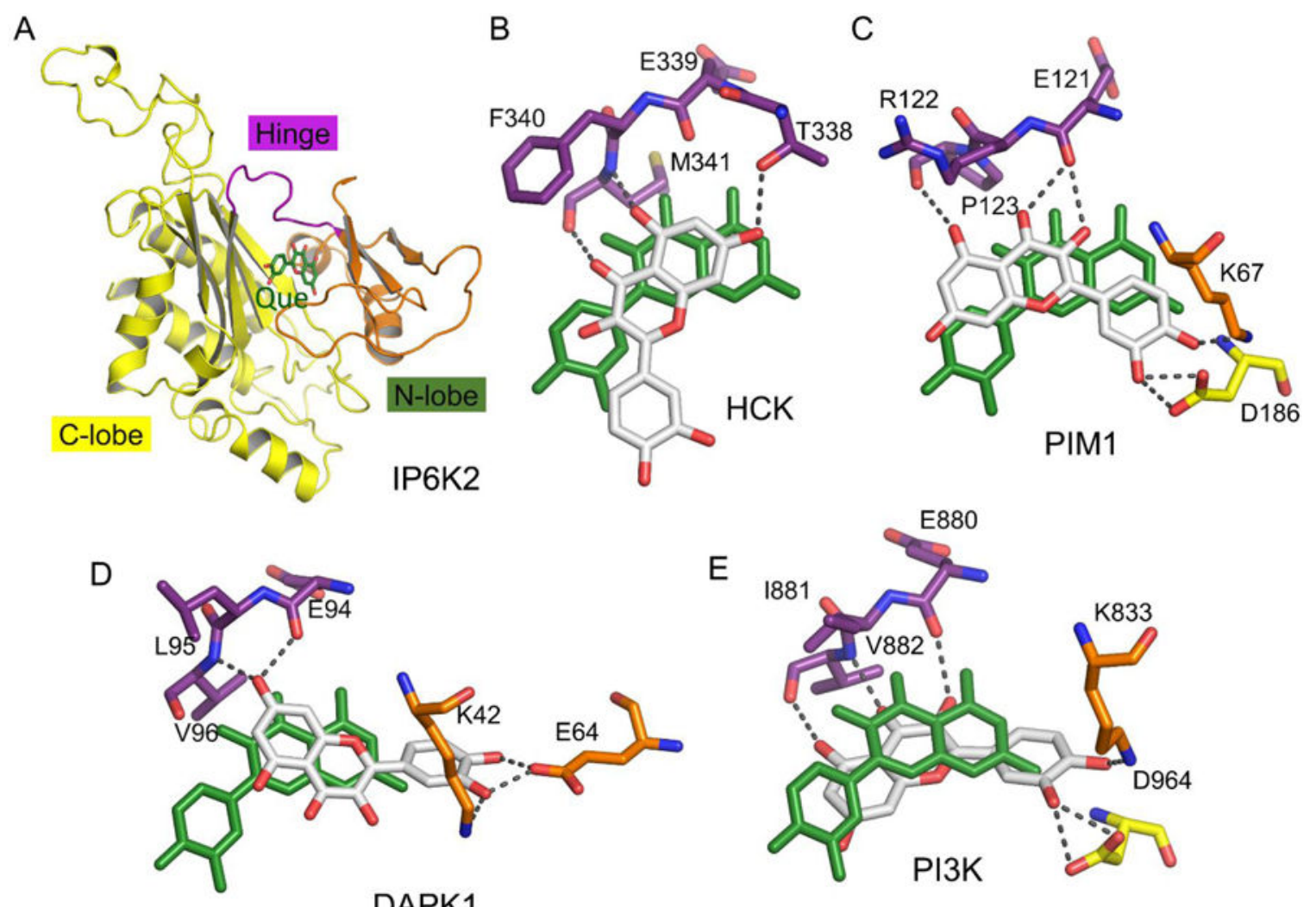

Fig. 4. Variations in the relative spatial positioning of 2 in various kinases.

A, Ribbon plot of a homology model of hIP6K2 ${ }^{24}$ into which $\mathbf{2}$ is docked; color coding is as in Fig. 2. B-E, by using the conserved nucleotide binding residues such as hinge region, metal binding residues and invariant lysine, the pose of $\mathbf{2}$ in the hIPMK crystal complex (green stick model) is superimposed upon the configuration of $\mathbf{2}$ (light gray stick model; oxygen atoms are shown in red; broken dark gray lines depict polar contacts) for the following kinase/2 crystal complexes: B, HCK (PDB = 2HCK); C, PIM1 (PDB = 2O3P); D, $(\mathrm{PDB}=5 \mathrm{AUW}) ; \mathbf{E}, \mathrm{PI} 3 \mathrm{~K}(\mathrm{PDB}=1 \mathrm{E} 8 \mathrm{~W})$. 
A

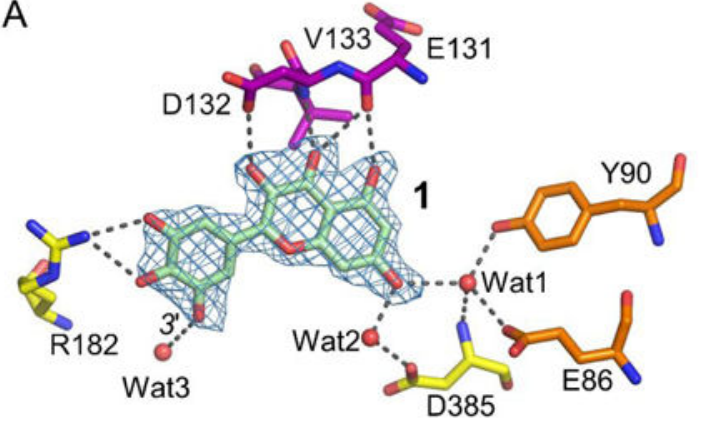

C

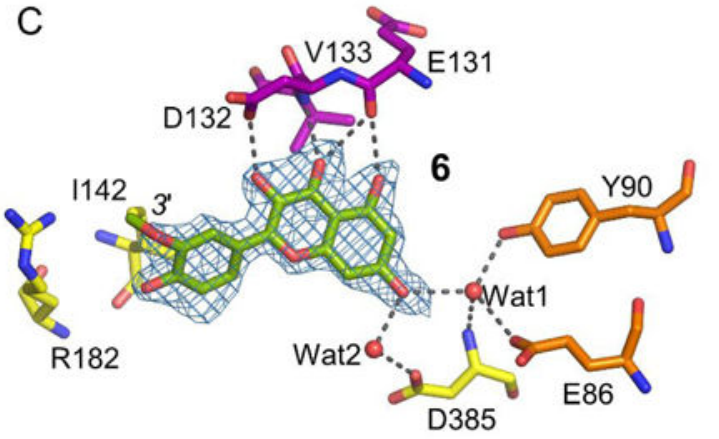

E

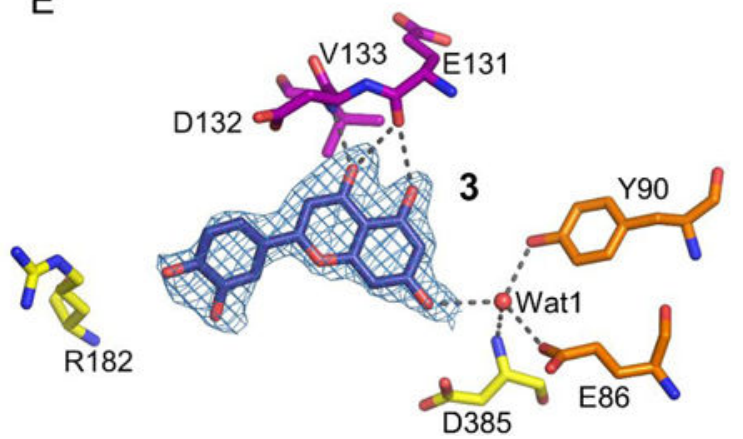

B

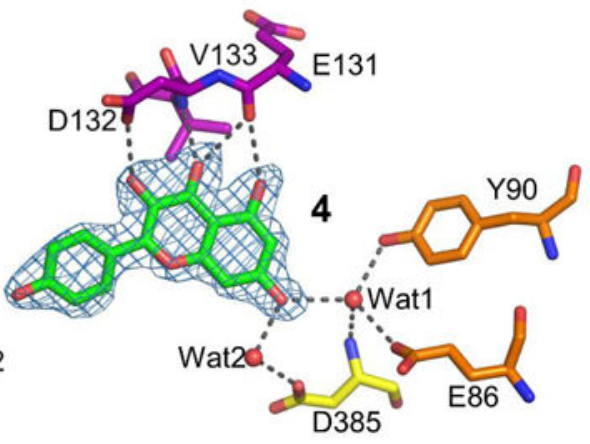

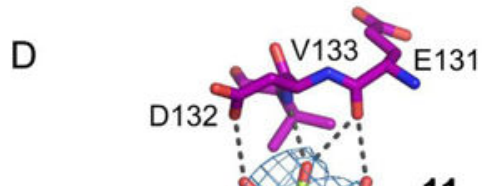

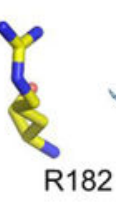

11

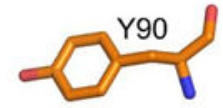

R182

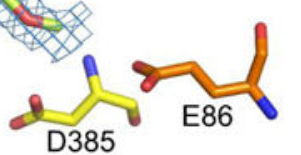

$\mathrm{F}$
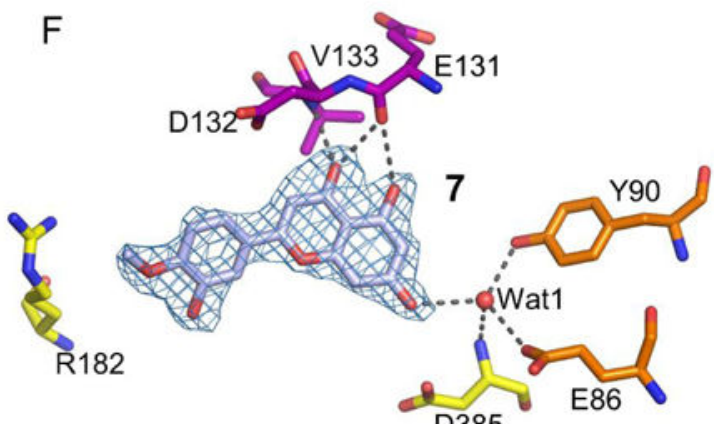

Fig. 5. Crystal structure of hIPMK in complex with various flavonoids.

A-F depict the data obtained from X-ray crystallographic analysis of selected flavonoids soaked into the crystal structure of hIPMK. A $2 \mathrm{Fo}-\mathrm{Fc}$ map of each bound compound is shown (skyblue mesh), contoured at $1 \sigma$. Broken lines depict hydrogen-bond interactions with associated water molecules and key residues. To highlight a rotamer switch, the groups attached to the 3'-carbon on the phenyl ring are annotated for compounds $\mathbf{1}$ and $\mathbf{6}$ (panels A and $\mathrm{C}$, respectively). 
A

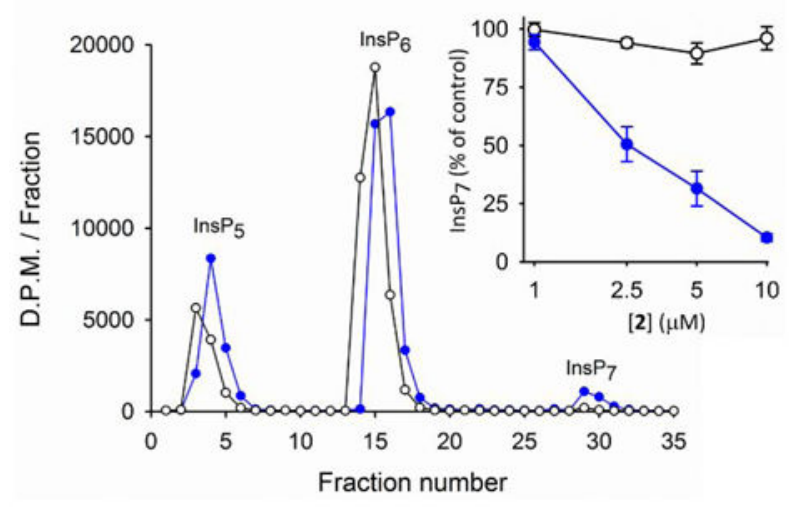

C

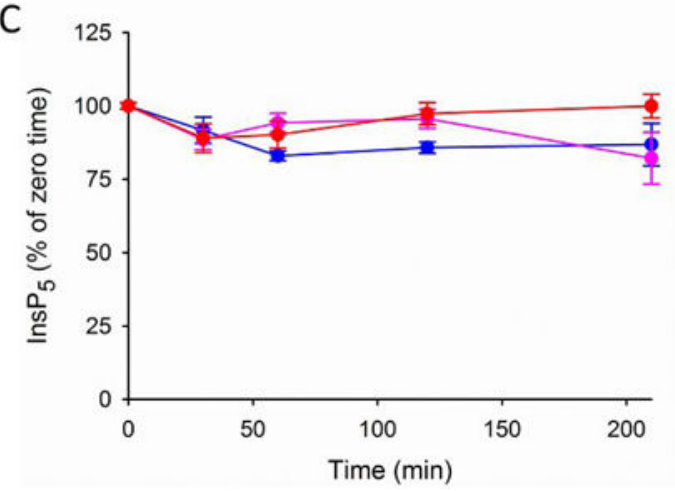

B

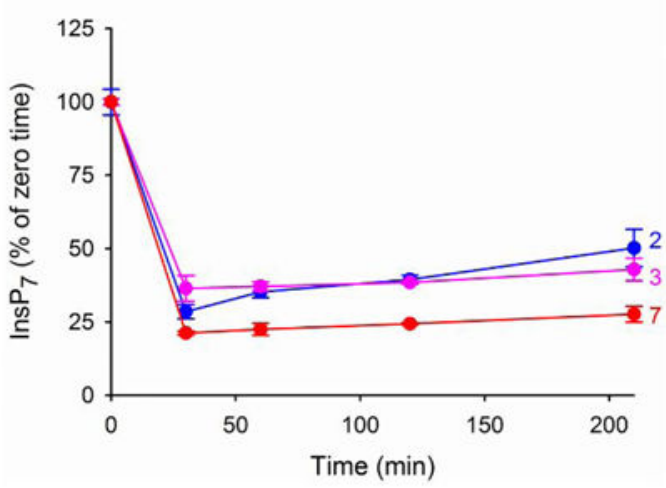

D

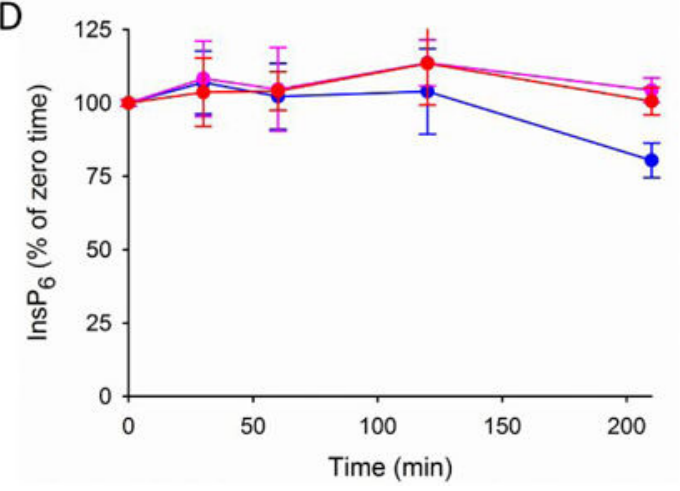

Fig. 6. HPLC analysis of the time-dependent effects of selected flavonoids $(2,3$ and 7$)$ upon InsP $_{5}$, InsP $P_{6}$ and InsP $_{7}$ in $\mathrm{HCT}_{116}$ cells.

A, Representative HPLC analysis of cell extracts prepared from $\left[{ }^{3} \mathrm{H}\right]$ inositol-labeled HCT116 cells incubated for $3.5 \mathrm{~h}$ with either DMSO vehicle (open circles) or $10 \mu \mathrm{M} 2$ (blue circles). The total DPM for each peak is: control, $\operatorname{InsP}_{5}=14677 ; \operatorname{InsP}_{6}=36,327 ; \operatorname{InsP}_{7}=$ 2160; treated with $2, \operatorname{InsP}_{5}=10,989 ; \operatorname{InsP}_{6}=39521 ; \operatorname{InsP}_{7}=195$. The inset shows the relative levels of $\mathrm{InsP}_{7}$ in cells treated for $3.5 \mathrm{~h}$ with either the indicated concentration of 2 (blue circles) or corresponding DMSO vehicle controls (open circles). B-D, HCT116 cells were treated with $2.5 \mu \mathrm{M}$ of either $\mathbf{2}$ (data colored blue), $\mathbf{3}$ (pink) or $\mathbf{7}$ (red) for the indicated times. Levels of the following InsPs were assayed by HPLC: $\mathbf{B}, \operatorname{InsP}_{7}, \mathbf{C}, \operatorname{InsP}_{5}, \mathbf{D}, \operatorname{InsP}_{6}$. Data are means \pm standard errors $(n=3-4)$. 
A

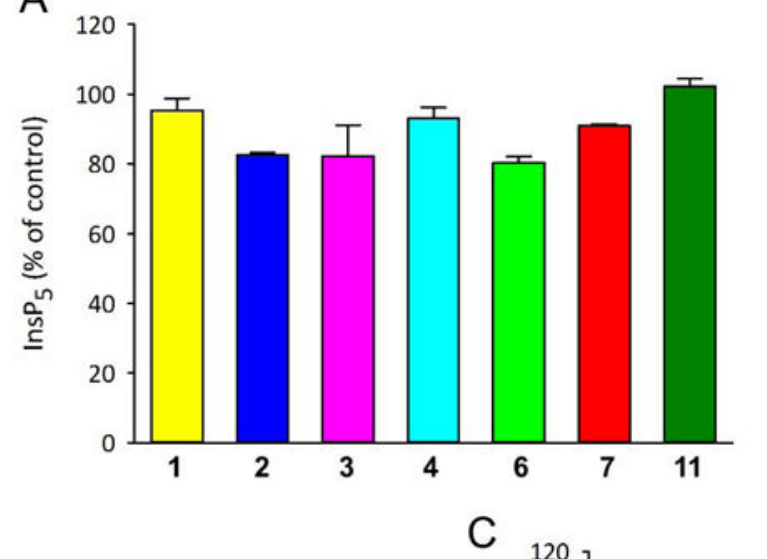

B

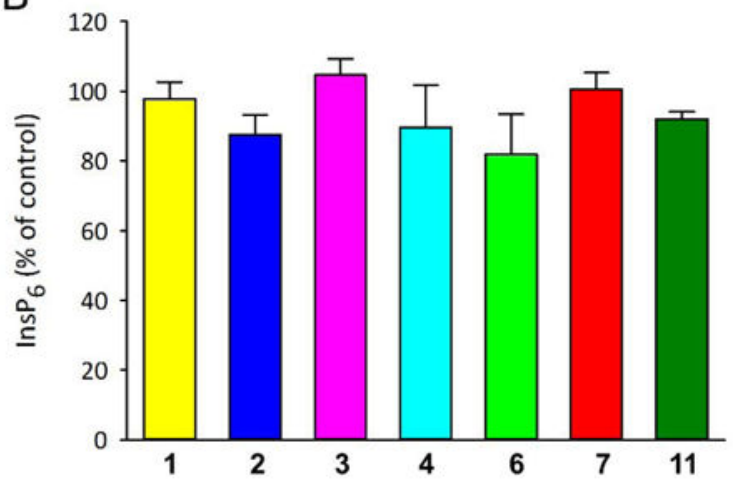

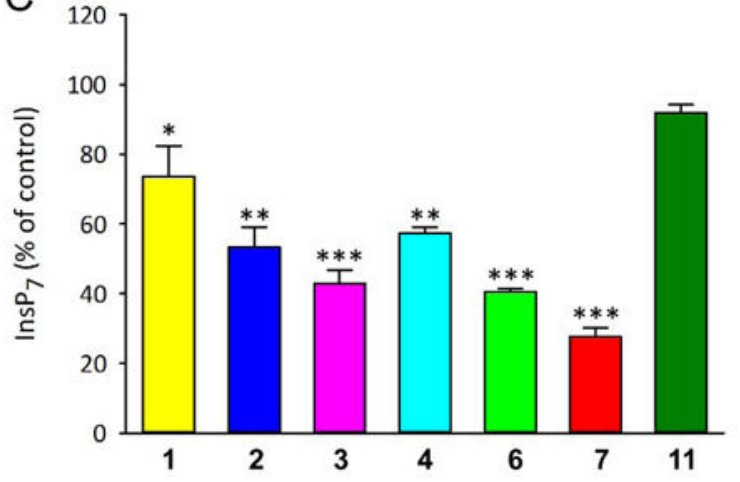

Fig. 7. The effects of flavonoids upon the InsP profile in HCT116 cells.

A-C Levels of the indicated InsPs in HCT116 cells were determined by HPLC as described in the legend to Fig. $6 \mathrm{~A}$, following $3.5 \mathrm{~h}$ treatment with $2.5 \mu \mathrm{M}$ of the indicated flavonoids. $\mathbf{A}, \mathrm{InsP}_{5}, \mathbf{B}, \mathrm{InsP}_{6}, \mathbf{C}, \mathrm{InsP}_{7}$. Data are means \pm standard errors $(\mathrm{n}=3-4)$; data for $\mathbf{2 , 3}$ and $\mathbf{7}$ are included from Fig. 5 for comparative purposes (using the same color-coding). $*$, $<$ $0.05 ; * *, \mathrm{p}<0.02 ; * * *, \mathrm{p}<0.001$, all versus controls. 
A

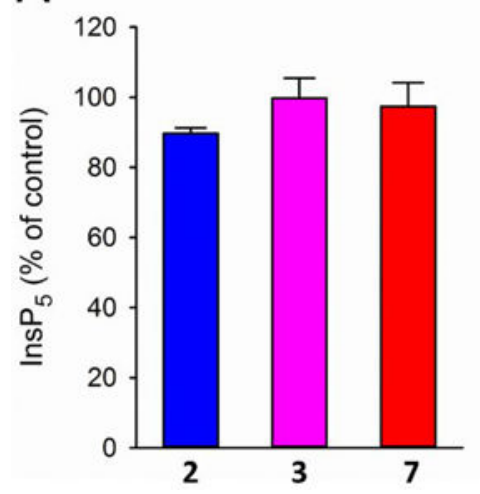

B

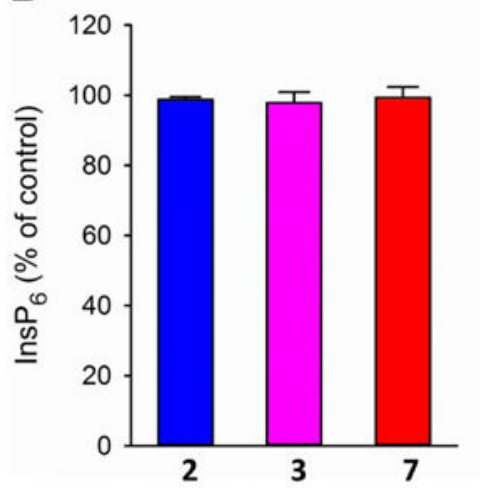

C

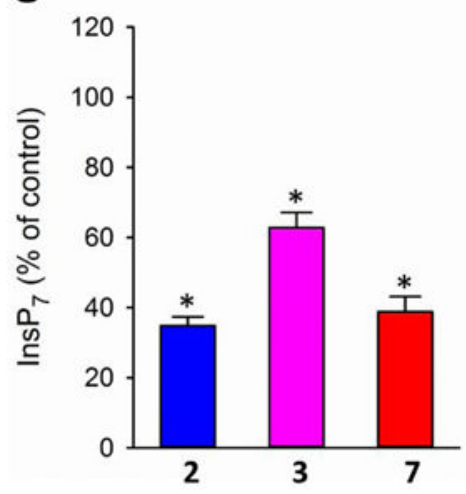

Fig. 8. The effects of flavonoids upon the InsP profile in HEK293 cells.

A-C Levels of the indicated InsPs in HCT116 cells were determined by HPLC as described in the legend to Fig. $6 \mathrm{~A}$, following $3.5 \mathrm{~h}$ treatment with $2.5 \mu \mathrm{M}$ of the indicated flavonoids. $\mathbf{A}, \mathrm{InsP}_{5}, \mathbf{B}, \mathrm{InsP}_{6}, \mathbf{C}, \mathrm{InsP}_{7}$. Data are means \pm standard errors $(\mathrm{n}=3) ;{ }^{*} \mathrm{p}<0.05$ versus corresponding control values. 
A

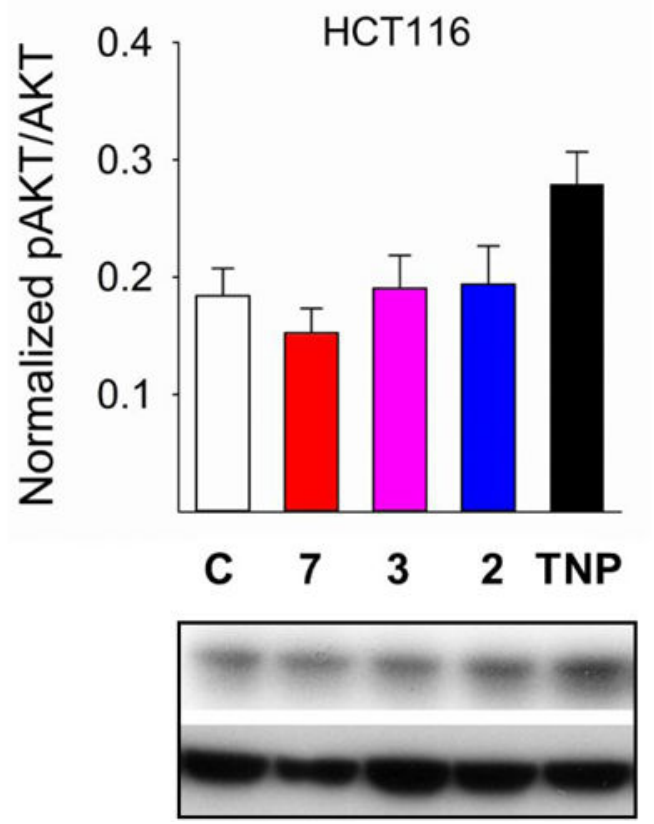

B

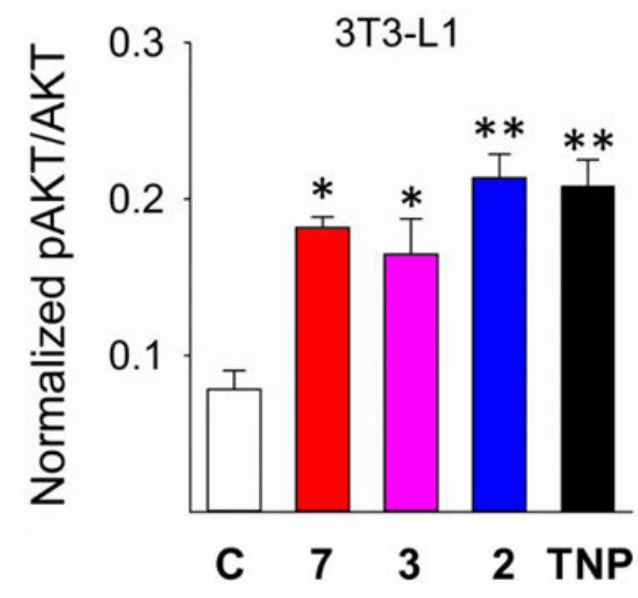

pAKT (T308)

AKT

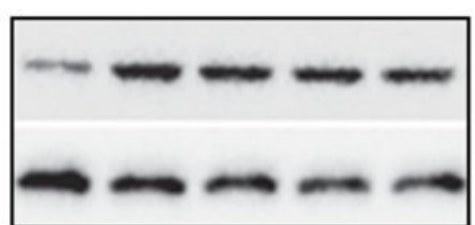

Fig 9. The effects of flavonoids and TNP upon AKT activity in HCT116 cells and 3T3-L1 fibroblasts.

Western analysis of AKT activity (T308 phosphorylation) and total AKT in A, HCT116 cells and B, 3T3-L1 pre-adipocytes, in each case following cell treatment for $3 \mathrm{~h}$ with either DMSO vehicle control (C), TNP, or $2.5 \mu \mathrm{M}$ of either $\mathbf{2 , 3}$, or $\mathbf{7}$. The upper panels depict means \pm standard errors $(\mathbf{A}, n=5 ; \mathbf{B}, n=3)$ as a ratio of p-AKT (phosphorylated AKT; T308), versus total AKT. The lower panels provide representative Western blots. Color-coding facilitates comparisons with the data in Figs 6 and 7. *p $<0.01$;* $\mathrm{p}<0.001$, vs control. 
Table 1.

\section{IC $_{50}$ data for inhibition of hIPMK and hIP6K2 by various flavonoids.}

The two enzymes were assayed in vitro as described under Experimental Procedures, using compound concentrations of up to $100 \mu \mathrm{M}$. Data shown are means \pm standard errors. In all cases where the $\mathrm{IC}_{50}$ is designated as $>30 \mu \mathrm{M}$, a combination of weak inhibition and poor curve fitting together prevented an accurate designation of $\mathrm{IC}_{50}$ values.

\begin{tabular}{|c|c|c|c|c|c|c|}
\hline Compound & Common name & $\underline{\operatorname{IP6K2}} \mathrm{IC}_{50}(\mu \mathrm{M})$ & $\mathbf{n}$ & $\underline{\operatorname{IPMK}} \mathrm{IC}_{50}(\mu \mathrm{M})$ & $\mathbf{n}$ & $\underline{\mathrm{IC}}_{50} \underline{\text { Ratio }}$ IP6K/IPMK \\
\hline 1 & Myricetin & $0.7 \pm 0.11$ & 9 & $1.1 \pm 0.2$ & 7 & 1.6 \\
\hline 2 & Quercetin & $0.7 \pm 0.13$ & 9 & $2.3 \pm 0.4$ & 6 & 3.3 \\
\hline 3 & Luteolin & $1.3 \pm 0.3$ & 6 & $5.5 \pm 1.2$ & 6 & 4.2 \\
\hline 4 & Kaempferol & $2.5 \pm 1.0$ & 7 & $4.4 \pm 1.4$ & 4 & 1.8 \\
\hline 5 & Apigenin & $7.1 \pm 2$ & 7 & $29 \pm 8$ & 8 & 4.1 \\
\hline 6 & Isorhamnetin & $0.5 \pm 0.06$ & 5 & $2.2 \pm 0.6$ & 3 & 4.4 \\
\hline 7 & Diosmetin & $0.9 \pm 0.18$ & 9 & $7.2 \pm 0.2$ & 3 & 8.0 \\
\hline 8 & Acacetin & $5.7 \pm 2$ & 7 & $>30$ & 6 & $>5.3$ \\
\hline 9 & $5,3^{\prime}, 4^{\prime}$-Trihydroxyflavone & $8.0 \pm 1.3$ & 5 & $>30$ & 7 & $>3.8$ \\
\hline 10 & Genkwanin & $24 \pm 8$ & 4 & $>30$ & 7 & $>1.3$ \\
\hline 11 & Rhamnetin & $1.8 \pm 0.2$ & 8 & $14 \pm 1$ & 3 & $>7.8$ \\
\hline 12 & 7,4'-Dihydroxyflavone & $18.3 \pm 3.6$ & 6 & $>30$ & 7 & $>1.6$ \\
\hline 13 & 6,4'-Dihydroxyflavone & $12.9 \pm 3.2$ & 4 & $>30$ & 8 & $>2.3$ \\
\hline 14 & 5,4'-Dihydroxyflavone & $>30$ & 5 & $>30$ & 7 & - \\
\hline 15 & 3',4'-Dihydroxyflavone & $11.4 \pm 1.7$ & 6 & $>30$ & 5 & $>2.6$ \\
\hline 16 & Eriodictyol & $25.3 \pm 7.5$ & 4 & $>30$ & 4 & $>1.2$ \\
\hline 17 & Naringenin & $>30$ & 5 & $>30$ & 5 & - \\
\hline
\end{tabular}

